\title{
INFERÊNCIA DE MUDANÇAS CLIMÁTICAS NA REGIÃO DE MANAUS (AM) USANDO DADOS GEOTERMAIS E METEOROLÓGICOS
}

\author{
Flavio Natal Mendes de Oliveira ${ }^{1}$, Rutenio Luiz Castro de Araújo², \\ João da Silva Carvalho ${ }^{3}$ e Clauzionor Lima da Silva ${ }^{4}$ \\ Recebido em 24 outubro, 2005 / Aceito em 8 maio, 2006 \\ Received on October 24, 2005 / Accepted on May 8, 2006
}

\begin{abstract}
The main objective of this study was to detect microclimate changes in Manaus City (AM), Brazil in attempting to indicate the possible causes for the fluctuations and trends observed. Meteorological and shallow geothermal records were analyzed. The meteorological data indicated an increment of $0.27 \pm 0.04^{\circ} \mathrm{C}$ in the mean surface air temperature during the last 80 years with reference to the 1950-1979 climatological mean. This increment has not been continuous, but it is modulated by frequency of El Niño, La Niña e Neutral events over the tropical Pacific Ocean, Niño 3.4 region. An increment of $3.17 \pm 0.53^{\circ} \mathrm{C}$ was determined from geothermal data from the second-half of the 19th century, which is likely associated with the land-use changes. From shallow geothermic data under sites with vegetation cover we verified that transient perturbations are good indicators of recent annual climate variability, while analysis of temperature profiles data under sites without vegetation cover seem to indicate microclimate changes related to the anthropogenic actions like deforest and urbanization action.
\end{abstract}

Keywords: Microclimate Changes, Geothermal Data, Anthropogenic Actions, ENSO, PDO.

RESUMO. 0 principal objetivo deste estudo foi detectar mudanças no microclima da cidade de Manaus (AM), Brasil e procurar indicar as possíveis causas destas flutuações e tendências observadas. Foram utilizados dados meteorológicos e da geotermia rasa. Através de dados meteorológicos determinamos um incremento nas temperaturas médias do ar de $0,27 \pm 0,04^{\circ} \mathrm{C}$, durante os últimos 80 anos, baseado na normal climatológica de 1950 a 1979 . Este incremento não tem sido contínuo, mas modulado pelas freqüências de meses com El Niño, La Niña e Neutros, detectados no Oceano Pacifico tropical, Região Niño 3.4. Através de dados geotérmicos determinamos um incremento de $3,17 \pm 0,53^{\circ} \mathrm{C}$, que se estima esteja relacionado com o uso do solo, desde a segunda metade do século XIX. Verificamos que as perturbações transientes do subsolo de locais com cobertura vegetal são bons indicadores das variabilidades climáticas anuais recentes e que as análises dos perfis sob locais sem cobertura vegetal indicam mudanças no microclima atribuídas às atividades antrópicas, tais como, o desflorestamento e urbanização.

Palavras-chave: Mudanças Microclimáticas, Dados Geotérmicos, Atividades Antrópicas, ENOS, ODP.

\footnotetext{
${ }_{1}^{1}$ Departamento de Geociências, Universidade Federal do Amazonas, Instituto Nacional de Meteorologia, Rua Recife 1041, Adrianópolis, 69057-001 Manaus, Amazonas, Brasil. Tel: (92) 36335353 - E-mail: natal@inmet.gov.br

2 Departamento de Geociências, Universidade Federal do Amazonas, Avenida General Rodrigo Otávio Jordão Ramos, 3000, Campus Universitário, Coroado, Setor Sul, Bloco I, Campus Universitário, 69077-000 Manaus, Amazonas, Brasil. Tel: (92) 3647-4025 - E-mail: ruie@ufam.edu.br.

3 Departamento de Geociências, Universidade Federal do Amazonas, Avenida General Rodrigo Otávio Jordão Ramos, 3000, Campus Universitário, Coroado, Setor Sul, Bloco I, Campus Universitário, 69077-000 Manaus, Amazonas, Brasil. Tel: (92) 3647-4025 - E-mail: jscarvalho@ufam.edu.br

${ }^{4}$ Departamento de Geociências, Universidade Federal do Amazonas, Avenida General Rodrigo Otávio Jordão Ramos, 3000, Campus Universitário, Coroado, Setor Sul, Bloco I, Campus Universitário, 69077-000 Manaus, Amazonas, Brasil. Tel: (92) 3647-4025 - E-mail: clauzionor_silva@hotmail.com
} 


\section{INTRODUÇÃ̃o}

Nas últimas décadas, muito se tem discutido sobre "aquecimento global". Entretanto, algumas questões pertinentes são demais complexas e necessitam de melhor entendimento, como, por exemplo: 0 aquecimento global está mesmo relacionado às altas emissões de gases preconizados pelos modelos sobre 0 efeito estufa? Este aquecimento é um processo de flutuação natural ou é devido à era industrial, ao desmatamento e ao concomitante aumento dos gases propícios ao efeito estufa, tal como o Dióxido de Carbono $\left(\mathrm{CO}_{2}\right)$ ? 0 conhecimento dos processos antrópicos e naturais nos períodos pré e pós-industrial, podem ajudar a melhor entender estes questionamentos.

Os métodos para a identificação dos mecanismos modificadores do clima e suas variantes têm advindo de diversas áreas da ciência, destacando-se os métodos paleoclimáticos diretos e indiretos (pré-instrumentais) e os meteorológicos diretos (instrumentais). Os dados meteorológicos ainda são a maneira mais segura de inferência climática, contudo, os registros não ultrapassam 100 anos de observação e torna-se necessário extrair informações através de métodos paleoclimáticos. Neste trabaIho, optou-se pelo uso da geotermia rasa como fonte de dados pré-instrumentais para inferir mudanças no microclima da cidade de Manaus-AM, pois apresenta uma série de vantagens, como: medições diretas do campo da temperatura; melhor sensibilidade às tendências de temperaturas ocorridas nos últimos 500 anos; boa espacialização continental; e melhor continuidade dos dados do que sensibilidade sazonal (Beltrami \& Harris, 2001).

Conciliar diretamente a base de informações da geotermia rasa com os registros meteorológicos é de difícil solução, porque a temperatura do solo, em superfície, não pode ser diretamente relacionada com a temperatura do ar superficial, que usualmente é obtida a 2 metros acima do solo, onde é normal a agitação térmica pela turbulência mecânica do ar.

As variações sazonais das temperaturas superficiais do ar na Amazônia são anualmente influenciadas pelas variabilidades dos mecanismos dinâmicos que produzem convecção, formação de nuvens e chuva. Estes mecanismos têm sido amplamente estudados nas últimas décadas (Molion, 1987; Kayano \& Moura,1986; Rao \& Hada,1987). Segundo Molion (1991), as variabilidades das precipitações na Amazônia estão, com certeza, associadas às variabilidades temporais e espaciais das fontes de calor latente equatoriais. Um dos fenômenos que sensivelmente modifica as posições e intensidades destas fontes de calor latente é 0 fenômeno El Niño / Oscilação do Sul (ENOS) no Oceano Paćífico Equatorial. Isto enfatiza a importância das condições térmicas dos oceanos sobre as temperaturas nos continentes, por meio de células atmosféricas que transportam calor e massa.

Neste contexto, investigamos a distribuição das temperaturas superficiais do Oceano Pacífico. Mantua et al. (1997), analisando uma série de registros climáticos da Bacia do Pacífico, verificaram um padrão de oscilação de 20 a 30 anos nas temperaturas superficiais do mar (TSM), denominadas de Oscilação Decadal do Pać́fico (ODP) e que, como o ENOS (EI Niño / Oscilação do Sul), possui fases fria e quente. A fase fria tem por característica apresentar padrões de anomalias negativas de TSM sobre as águas do Oceano Pacífico Tropical e, simultaneamente, anomalias positivas de TSM sobre as águas do Oceano Pacífico Norte Extratropical, enquanto que a fase quente caracteriza-se por anomalias positivas de TSM no Oceano Pacífico Tropical e anomalias negativas sobre o Oceano Pacífico Extratropical. Os mesmos autores identificaram que, durante a fase fria da ODP, há maior freqüência de La Niñas, enquanto que durante a fase quente da ODP, há maior freqüência de El Niños e identificaram 3 fases predominantes ODP: quente (1925-1946), fria (1947-1976) e quente (1976-1998).

Molion (2004) descreveu que as anomalias da temperatura média global apresentaram uma tendência negativa aproximada de $-0,15^{\circ} \mathrm{C}$, durante a fase predominante fria da ODP (194776) e, coincidentemente, uma tendência positiva de $+0,30^{\circ} \mathrm{C}$ durante períodos de maior freqüência de EI Niños. 0 autor sugere que a ODP entrou em sua fase fria desde 1999.

Segundo, o informe de 2001 do "Climate Change" do "Intergovernmental Panel on Climate Change" (IPCC), a média global do aquecimento em superfície mediante registros instrumentais é de $+0,6 \pm 0,2^{\circ} \mathrm{C}$ desde 0 final do século XIX. Grande parte deste aquecimento teria ocorrido de 1910 a 1945 e a partir de 1976 (IPCC, 2001).

Dos dados geotérmicos é registrado, com relativa freqüência na literatura, que as perturbações térmicas provocadas pelo fluxo de radiação solar incidente na superfície terrestre propagam-se para 0 subsolo, sendo ao longo do tempo atenuadas com 0 incremento da profundidade, manifestando-se como perturbações no campo geotérmico, resultado das variações climáticas de superfície (Silva, 2003; Astier, 1975; Beck, 1965; Bowen, 1966; Carslaw \& Jaeger, 1959). 0 uso destas perturbações térmicas do subsolo para investigações climáticas em diversas partes do nosso planeta foi feito por Birch (1948), Cermak (1971), Beck (1982), e Lachenbruch \& Marshall (1986), que ressaltaram a importância das informações contidas nos perfis geotérmicos nos estudos sobre 0 aquecimento global na superfície. Na América do Sul, o método dos perfis geotérmicos foi iniciado por Hamza $(1991,1998)$. 
Roy et al. (1971) determinaram um acréscimo nos valores das temperaturas médias superficiais do solo de $5^{\circ} \mathrm{C}$ em um período de 50 anos, para a região de Cambridge, Massachusetts (USA). Segundo os autores, tal acréscimo foi decorrente da construção de edifícios na região em pauta. Outros estudos de dados geotérmicos indicaram um aquecimento de 2 a $5^{\circ} \mathrm{C}$ na região ártica do Alaska (Lachenbruch \& Marshall, 1986) e conforme o IPCC (2001), o aquecimento global medido por dados geotérmicos é de aproximadamente $1,0 \pm 0,3^{\circ} \mathrm{C}$, durante os últimos 500 anos, com maior atribuição a partir do século XIX. Com base em 826 perfis geotérmicos ao redor do globo terrestre, 0 aquecimento global é de aproximadamente $0,45^{\circ} \mathrm{C}$ nos últimos 200 anos e de $0,9^{\circ} \mathrm{C}$ nos últimos cinco séculos (Beltrami \& Harris, 2001).

Na região amazônica, recentes trabalhos científicos registraram perturbações diurnas e sazonais em profundidades de até 250 metros (Serra, 2002), permitindo concluir que tais variações persistem a maiores profundidades (Araujo, 1987; Souza et al., 1989).

Neste presente trabalho analisamos séries de dados meteorológicos e geotérmicos, com a atribuição principal de quantificar as recentes variabilidades $e$ as mudanças de longa data da temperatura média anual local da cidade de Manaus-AM, e estimar tais tendências para locais de recente ocupação.

\section{HISTÓRICO DA OCUPAÇÃO}

A região de Manaus contava em 1754 com apenas 200 habitantes e após cem anos de ocupação já havia cerca de 4.000 habitantes (Pontes Filho, 2000). Segundo Salati (1987), no período compreendido entre 1840 a 1910, intensificou-se a colonização da Amazônia e cerca de 600 mil a 800 mil migrantes penetraram na Amazônia, que culminou com o rápido desenvolvimento de importantes centros urbanos, como Manaus e Belém; todavia, somente com 0 advento da Zona Franca de Manaus, na década de 1970, é que a cidade de Manaus apresentou um crescimento constante, passando de 284.000 habitantes em 1970, para $635.000 \mathrm{em} 1980$ e $1.100 .000 \mathrm{em} 1990$. No ano de 2005, Manaus atingiu uma população de aproximadamente 1.644 .690 habitantes (IBGE, 2005).

\section{OBTENÇÃO E EMPREGO DOS DADOS GEOTERMAIS}

Os métodos propostos para determinar a história das temperaturas na superfície do solo geralmente assumem difusividades e condutividades térmicas constantes e tais formulações matemáticas podem, apenas, representar de forma simplificada os efeitos térmico-temporais ocorridos na interface solo-atmosfera. 0 ideal seria obter amostras do material litológico e calcular suas difusividades e condutividades térmicas, bem como monitorar um pulso térmico gerado em superfície, contudo, por não ter sido realizado tal experimento, bem como a aquisição de tais amostras, ficou impossibilitado, no presente trabalho, o cálculo mais apurado.

Pelo exposto, para determinar o tempo da variação das temperaturas, consideramos a hipótese de Roy et al. (1971) de um perfil geotérmico inicial, referente ao período anterior às atividades antrópicas. Primeiramente, para este perfil inicial, assumimos três condições básicas: o material litológico é homogêneo, está termicamente em equilíbrio e a superfície terrestre assume comportamento adiabático. 0 resultado é que o perfil geotérmico inicial começaria na superfície com o valor da temperatura média anual superficial do solo, anterior às atividades antrópicas, doravante denominada de $T_{L D}$, e os valores de temperatura aumentariam, gradual e linearmente, com a profundidade, visto que as variações térmicas neste perfil são funções, apenas, do fluxo de calor oriundo do interior da Terra.

Neste método somente foi possível obter as informações de $T_{L D}$ através do cálculo do perfil geotérmico inicial. As temperaturas médias anuais atuais superficiais do solo, doravante denominadas de $T_{S A}$, foram obtidas através do cálculo de um perfil geotérmico final. A variação temporal entre $T_{L D}$ e $T_{S A}$ foi estimada através de considerações, apenas, do uso do solo. Em nosso trabalho consideramos que na cidade de Manaus o perfil inicial faz referência a partir da segunda metade do século XIX, conforme 0 histórico do uso do solo.

Neste estudo analisamos os perfis geotérmicos de seis poços sob locais com cobertura vegetal (LCCV) e cinco poços sem cobertura vegetal (LSCV) com medições de temperatura realizadas em intervalos discretos de 5 metros, cujos pontos de observação estão distribuídos sobre a área urbana de Manaus, conforme representado na Fig. 1. Nas perfilagens rasas superficiais, até 0,20 $\mathrm{m}$, foram utilizadas sondas com sensor térmico de termopar, com precisão de $\pm 0,1^{\circ} \mathrm{C}$ (Araujo, 1999). Nas perfilagens mais profundas, o sensor térmico foi de termistor, com precisão de $\pm 0,01^{\circ} \mathrm{C}$ (Araujo, 1999). Assim, as temperaturas superficiais do solo, doravante denominadas de $T_{S p}$, foram obtidas com sensor térmico de termopar. As profundidades analisadas que apresentam sinais de perturbações térmicas de superfície constituemse palco da geotermia rasa.

Conforme Roy et al. (1971), a extrapolação da reta que determina o gradiente geotérmico profundo possibilita o cálculo da TLD. Conforme Araujo (1999), a extrapolação da reta, logo após 


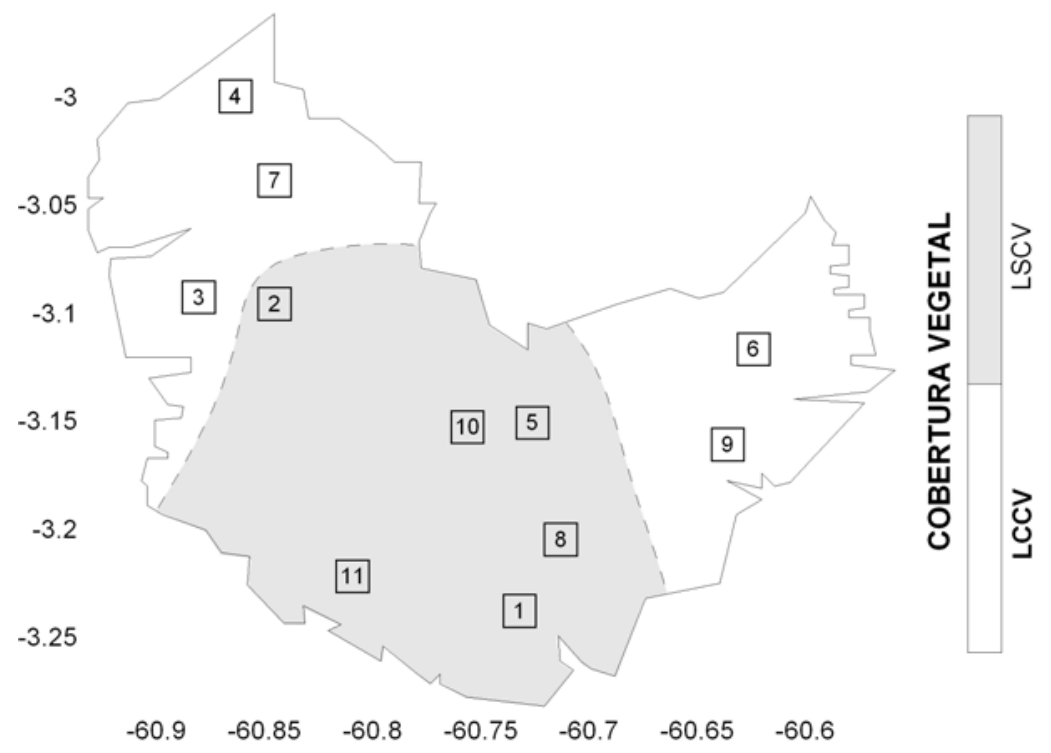

Figura 1 - Localização dos Perfis Geotérmicos em Manaus - AM.

a inversão térmica subsuperficial, possibilita 0 cálculo da $T_{S A}$. Logo, a T LD somente é obtida a partir das profundidades onde não sejam registradas influências oriundas das perturbações térmicas do clima de superfície, regiões denominadas de Zonas Termicamente Estáveis (ZTE). Toda a zona do subsolo, desde a superfície até a profundidade de início da ZTE, é denominada de Zona Termicamente Perturbada (ZTP).

Os valores da $T_{S A}$ e da $T_{L D}$ foram obtidos através do perfil geotérmico inicial, derivado de equações lineares calculadas, ponto a ponto, com o conhecimento prévio do gradiente geotérmico médio local. Os cálculos pontuais nos permitem obter os valores das temperaturas iniciais $\left(\mathbf{T}_{0}\right)$ em cada nível do perfil. As temperaturas iniciais se referem às temperaturas de um perfil supostamente estável, sem perturbações transientes. As seguintes equações lineares foram empregadas:

$$
\mathbf{T}_{0}=-\left(G_{Z T E} * Z-\mathbf{T}_{r e f}\right)
$$

e

$$
\left.\mathbf{T}_{0}=G_{Z T P} * Z+\mathbf{T}_{r e f}\right)
$$

onde os $\mathrm{G}_{\text {ZTE }}$ e $\mathrm{G}_{\text {ZTP }}$ São os gradientes geotérmicos médios para as zonas termicamente estáveis e termicamente perturbadas, respectivamente. Z é a profundidade no determinado nível e $\mathbf{T}_{r e f}$ é a temperatura ajustada de referência à superfície, a qual é igual a $T_{L D}$ na eq. 1 e a $T_{S A}$ na eq. 2.

0 conjunto de informações de longa data $\left(l_{\llcorner D}\right)$ e transientes ( $\left.\left.\right|_{T R}\right)$ foi obtido pela diferença entre o valor observado no perfil geotérmico e 0 valor calculado de $\mathbf{T}_{0}$ pelas eqs. 1 e 2 , respectivamente.

Para a obtenção dos valores definitivos das ILD's fez-se necessário eliminar as perturbações transientes $\left(I_{T R}\right)$, visto serem oriundas de variabilidades climáticas sazonais e anuais. Fez-se aqui a distinção entre variabilidades e mudanças climáticas, muito confundidas na literatura cientifica. Estatisticamente, assume-se que as variações anuais no estado médio do "tempo" denominamse de "variabilidades climáticas", e as variações eventuais detectadas por décadas e séculos, denominam-se "mudanças climáticas" (IPCC, 2001).

Assim sendo, o resultado das perfilagens geotérmicas rasas e profundas, da geotermia rasa, propiciam a obtenção dos dados necessários à realização de estudos climáticos locais.

\section{SÉRIES HISTÓRICAS DA OBSERVAÇÃO INSTRUMENTAL}

No presente trabalho foram analisados os registros dos valores das temperaturas médias mensais do ar, referentes aos anos de 1921 a 2000, e dos totais de precipitação pluviométrica referentes aos anos de 1961 a 2000, registrados na Estação Climatológica Principal do INMET.

Segundo normas da Organização Meteorológica Mundial (OMM), a média histórica do clima de uma determinada região deve ser calculada com base mínima de 30 anos. Neste trabaIho escolhemos o período de 1950-79 para 0 cálculo da média climatológica e neste aspecto a temperatura média anual do ar calculada foi de $26,65 \pm 0,33^{\circ} \mathrm{C}$. 


\section{ANOMALIAS DE TEMPERATURA DO AR E PRECIPITAÇÃO}

Com o objetivo de determinar como cada evento do ENOS contribui nas variabilidades da temperatura média do ar, distribuímos 0 ciclo de um ano em períodos trimestrais, classificados de acordo com padrões normais de precipitação pluviométrica, visto que nas regiões tropicais os conceitos de estação seca e estação chuvosa substituem o ciclo de temperaturas ocorrentes nas estações de latitudes médias (Riehl, 1965) e tais anomalias de precipitação influenciam diretamente sobre as anomalias de temperatura.

Os padrões normais de precipitação pluviométrica e a freqüência dos meses secos e chuvosos foram determinados pelo Método do "Índice dos Decis", originalmente desenvolvido por Gibbs \& Maher (1967). Tal método vem sendo usado desde 1969, no "Monthly Rainfall Review" do Serviço Meteorológico Australiano, o "Bureau Meteorology", como uma classificação geral da distribuição de freqüências de precipitação pluviométrica. № Brasil, o INMET vem utilizando este procedimento desde 2001.

A vantagem deste método é de que ele parte do princípio de que a distribuição de freqüência da precipitação pluviométrica e suas fronteiras apresentam grandes desvios relativos às distribuições gaussianas (normais). Todos os totais diários, vários mensais e sazonais e alguns anuais têm distribuições que notadamente não são normais e o conceito de média é substituído pelo conceito de normal. Outra característica que distingue as distribuições de freqüência da precipitação pluviométrica das de outros vários elementos meteorológicos é que os totais diários, alguns mensais e uns poucos anuais contêm valores de não ocorrência (zero). Deduz-se que o uso da média aritmética e o desvio padrão são realmente inadequados para o tratamento dos dados de precipitação pluviométrica e pode conduzir a conclusões erradas.

Tais freqüências dos desvios pluviométricos foram determinadas de 1961 a 2000 e consistem da análise de uma quantidade " $n$ " de dados de totais mensais de precipitação pluviométrica, dispostos em ordem ascendente de $\chi_{1}$ (menor valor) até $\chi_{n}$ (maior valor) e dividida em dez partes iguais ou dez decis $(D)$. Assim, cada valor de decil foi calculado pela seguinte equação:

$$
D=\chi_{j}+f\left(\chi_{j+1}-\chi_{j}\right)
$$

onde $f$ é a parte fracional do decil.

A demonstração dos valores padrões normais foi realizada através de distribuição empírica, sendo:

$$
D=\chi_{j} \text {, se } f=0 \text { e } D=\chi_{j+1} \text {, se } f>0
$$

Na Tabela 1 segue a terminologia usada:
Tabela 1 - Classificação dos Índices Decis.

\begin{tabular}{|c|c|c|c|}
\hline Classificação & $\begin{array}{c}\text { Intervalo } \\
\text { percentil }\end{array}$ & $\begin{array}{c}\text { Intervalo } \\
\text { Decil }\end{array}$ & $\begin{array}{c}\text { Índice } \\
\text { Decil }\end{array}$ \\
\hline Muito Chuvoso & superior a 90 & 10 & +3 \\
\hline Chuvoso & 80 a 90 & 9 & +2 \\
\hline Levemente Chuvoso & 70 a 80 & 8 & +1 \\
\hline Normal & 30 a 70 & 4 a 7 & 0 \\
\hline Levemente Seco & 20 a 30 & 3 & -1 \\
\hline Seco & 10 a 20 & 2 & -2 \\
\hline Muito Seco & inferior a 10 & 1 & -3 \\
\hline
\end{tabular}

Conseqüentemente, obtivemos curvas de distribuição normal, conforme apresentado na Fig. 2, que determinam os valores dos desvios. Nesta figura observa-se que a estação chuvosa em Manaus vigora de dezembro a maio. Os demais meses apresentam padrões muito inferiores.

Calculamos as anomalias das temperaturas médias do ar para o período de 1921 a 2000, utilizando-se a média climatológica de 1950 a 1979, e os valores assim obtidos foram relacionados com as anomalias de temperatura das águas do Pacífico, na região Niño $3.4\left(120^{\circ} \mathrm{W}-170^{\circ} \mathrm{W}\right.$ e $\left.5^{\circ} \mathrm{S}-5^{\circ} \mathrm{N}\right)$, obtidas de Trenbert \& Stepaniak (2001), que as calcularam com base no período médio de 1950 a 1979, a partir da série de dados do Hadley Centre Global Sea Ice and Sea Surface Temperature (HadISST) Analyses, desenvolvido pelo Met Office Hadley Centre, Reino Unido. 0 HadISST consta de uma série de dados de TSM de 1870 até a presente data, estimados por observações e derivados de produtos de satélite com resolução global $1^{\circ} \times 1^{\circ}$.

A escolha da média climatológica de 1950-79 deve-se à observação de Molion (2004), de que o período adotado pela OMM de 1961-90 (30 anos) para uso de médias climatológicas, poderia mascarar as tendências de longo-prazo, pois, desta referida média, 16 anos estiveram dentro da fase fria da ODP e 14 anos dentro da fase quente da ODP. Este autor salientou que se 0 efeito das duas fases sobre o clima forem contrários, teríamos uma média quase-perfeita no período, em que o estado do clima na primeira cancelaria o efeito da segunda. Assim, a média climatológica de 1950-79 vigorou em essência dentro de uma única fase da ODP e resolve o problema evidenciado no uso da média climatológica de 1961-90, sugerida pela OMM.

Para o cálculo de tendência da temperatura média do ar em Manaus, optou-se por uma análise de regressão linear simples do tipo:

$$
T=D * A+I
$$

onde, $T$ é a variável temperatura média, $D$ é a inclinação da reta, $A$ é 0 ano correspondente e $I$ é a interseção. 


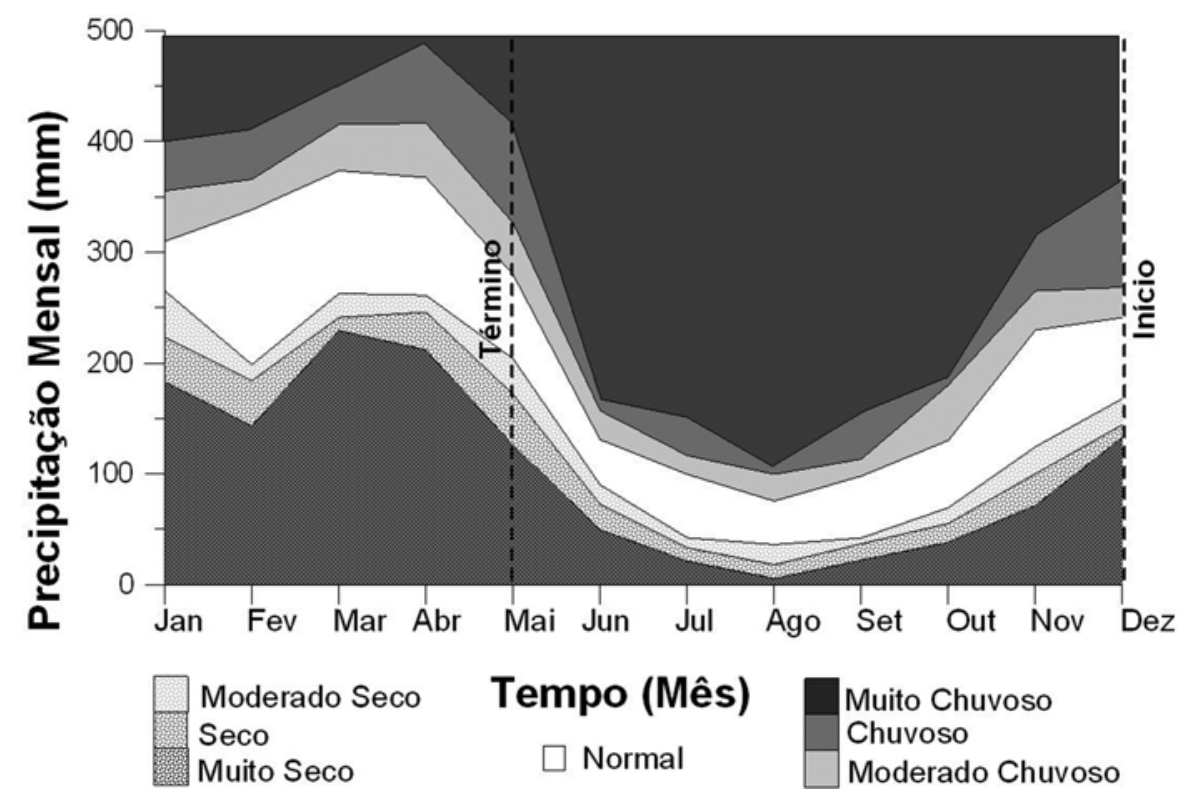

Figura 2 - Ilustração das Curvas de Distribuição Normal da Precipitação Pluviométrica em Manaus pelo Método dos Decis.

Os eventos do fenômeno El Niño / Oscilação do Sul (ENOS) foram classificados, conforme Trenbert (1997), para a região Niño 3.4, quando as anomalias de TSM na região excedem os valores de $+0,4^{\circ} \mathrm{C}$ e $-0,4^{\circ} \mathrm{C}$, respectivamente, e ainda persistem no mínimo por seis meses ou mais. Nas Tabelas de 2 a 4 apresentamos as anomalias das temperaturas médias do ar para os períodos da ODP e classificação de meses com eventos de El Niño e La Niña.

\section{DISCUSSÃO}

\section{Da Observação Instrumental}

Na região de Manaus, conforme os índices Decis (Tab. 1 e Fig. 2), os grupos climáticos trimestrais foram doravante denominados de 1TC ( $1^{\circ}$ trimestre chuvoso - de dezembro a fevereiro), 2TC $\left(2^{\circ}\right.$ trimestre chuvoso - de março a maio), 1TS ( $1^{\circ}$ trimestre seco - de junho a agosto) e 2TS ( $2^{\circ}$ trimestre seco - de setembro a novembro).

Referente aos dados de TSM do Pacífico, região Niño 3.4, foram classificados 322 meses com El Niño, 281 meses com La Niña e 352 meses neutros. Dos meses com El Niño, registrou-se 81 meses no trimestre 1TC, 80 meses no trimestre 2TC, 83 meses no trimestre 1TS e 78 meses no trimestre 2TS. Dos meses com La Niña, registrou-se 76 meses no 1TC, 58 meses no 2TC, 68 meses no 1 TS e 79 meses no 2TS. Tais informações são apresentadas nas Tabelas 2, 3 e 4, contudo, separadas por fases da ODP.
Na Figura 3 são traçados cruzamentos entre as anomalias de TSM na região NIÑO 3.4 com os índices dos decis. Nesta figura observa-se que a maior freqüência de meses secos está associada a eventos de El Niño, onde apenas $21,13 \%$ dos meses foram classificados como chuvosos (Fig. 3-a), enquanto que durante os eventos La Niña, 38,24\% dos meses foram classificados como chuvosos (Fig. 3-b). Tal comportamento dos desvios de precipitação influencia diretamente no comportamento anômalo das temperaturas médias; Quando analisamos os casos de meses neutros (Fig. 3-c) verificamos que os padrões seco e chuvoso ocorreram em estreita proporção.

Na Tabela 5 são extraídas informações simplificadas das Tabelas 2, 3 e 4 e acrescidas informações relevantes referentes aos meses Neutros. Observa-se na Tabela 5 que as anomalias negativas durante os trimestres de La Niña e Neutros contrapõem-se às tendências de aquecimento observadas nos trimestres sob influência de El Niño. Os eventos de El Niño têm contribuído na elevação das temperaturas médias em até $+0,39^{\circ} \mathrm{C}$ $\mathrm{e}+0,50^{\circ} \mathrm{C}$, durante os trimestres chuvosos $1 \mathrm{TC}$ e $2 \mathrm{TC}$, respectivamente. Isto é coerente, visto que tem sido observado que a variabilidade interanual da precipitação pluviométrica na América do Sul é modulada pelo ENOS (Kousky \& Cavalcanti, 1984) e na Amazônia, estudos indicam desvios negativos de precipitação pluviométrica durante eventos de El Niño (Kayano \& Moura, 1986; Aceituno, 1988). Isto acontece porque eventos de El Niño durante o período chuvoso na Amazônia Central afetam o posicionamento 
Tabela 2 - Anomalia trimestral da temperatura média do ar de superfície em Manaus, durante a fase quente da Oscilação Decadal do Pacífico, de 1925 a 1946.

\begin{tabular}{|c|c|c|c|c|c|c|c|c|c|c|c|}
\hline \multicolumn{12}{|c|}{ EVENTOS DE EL NIÑO } \\
\hline \multirow{2}{*}{ Início } & \multirow{2}{*}{ Fim } & Duração & \multicolumn{2}{|c|}{$1 \mathrm{TC}$} & \multicolumn{2}{|c|}{ 2TC } & \multicolumn{2}{|c|}{$1 \mathrm{TS}$} & \multicolumn{2}{|c|}{ 2TS } & \\
\hline & & Total & Duração & Anomalias & Duração & Anomalias & Duração & Anomalias & Duração & Anomalias & \\
\hline $\mathrm{Jul} / 25$ & ago/26 & 14 & 3 & 1,27 & 3 & 0,78 & 5 & 0,11 & 3 & 0,08 & 14 \\
\hline $\mathrm{Jul} / 29$ & $\mathrm{ago} / 31$ & 26 & 6 & $-0,20$ & 6 & 0,17 & 8 & 0,00 & 6 & $-0,06$ & 26 \\
\hline$\Sigma$ (meses) & Média $\left({ }^{\circ} \mathrm{C}\right)$ & 76 & 21 & 0,35 & 18 & 0,38 & 19 & 0,00 & 18 & 0,05 & 76 \\
\hline \multicolumn{12}{|c|}{ EVENTOS LA NIÑA } \\
\hline \multirow{3}{*}{ Início } & \multirow{3}{*}{ Fim } & Duração & \multicolumn{2}{|c|}{$1 \mathrm{TC}$} & \multicolumn{2}{|c|}{$2 \mathrm{TC}$} & \multicolumn{2}{|c|}{$1 \mathrm{TS}$} & \multicolumn{2}{|c|}{$2 \mathrm{TS}$} & \\
\hline & & Total & Duração & Anomalias & Duração & Anomalias & Duração & Anomalias & Duração & Anomalias & \\
\hline & & meses & meses & $\left({ }^{\circ} \mathrm{C}\right)$ & Meses & $\left({ }^{\circ} \mathrm{C}\right)$ & meses & $\left({ }^{\circ} \mathrm{C}\right)$ & Meses & $\left({ }^{\circ} \mathrm{C}\right)$ & $\Sigma$ \\
\hline $\mathrm{Jul} / 42$ & $\mathrm{abr} / 43$ & 10 & 3 & $-0,59$ & 2 & $-0,82$ & 2 & $-0,70$ & 3 & 0,01 & 10 \\
\hline Jan/45 & fev/46 & 14 & 5 & $-0,27$ & 3 & $-0,32$ & 3 & 0,25 & 3 & $-0,10$ & 14 \\
\hline$\Sigma$ (meses) & Média $\left({ }^{\circ} \mathrm{C}\right)$ & 58 & 17 & $-0,53$ & 12 & $-0,44$ & 14 & $-0,22$ & 15 & $-0,29$ & 58 \\
\hline
\end{tabular}

Tabela 3 - Anomalia trimestral da temperatura média do ar de superfície em Manaus, durante a fase fria da Oscilação Decadal do Pacífico, de 1947 a 1976.

\begin{tabular}{|c|c|c|c|c|c|c|c|c|c|c|c|}
\hline \multicolumn{12}{|c|}{ EVENTOS EL NIÑO } \\
\hline \multirow{2}{*}{ Início } & \multirow{2}{*}{ Fim } & Duração & \multicolumn{2}{|c|}{ 1TC } & \multicolumn{2}{|c|}{$2 \mathrm{TC}$} & \multicolumn{2}{|c|}{ 1TS } & \multicolumn{2}{|c|}{ 2TS } & \\
\hline & & Total & Duração & Anomalias & Duração & Anomalias & Duração & Anomalias & Duração & Anomalias & \\
\hline & & meses & meses & $\left({ }^{\circ} \mathrm{C}\right)$ & Meses & $\left({ }^{\circ} \mathrm{C}\right)$ & Meses & $\left({ }^{\circ} \mathrm{C}\right)$ & Meses & $\left({ }^{\circ} \mathrm{C}\right)$ & $\Sigma$ \\
\hline jun/51 & $\mathrm{mar} / 52$ & 10 & 3 & $-0,39$ & 1 & $-0,37$ & 3 & $-0,05$ & 3 & $-0,36$ & 10 \\
\hline fev/53 & jan/54 & 12 & 3 & 0,17 & 3 & 0,38 & 3 & 0,85 & 3 & 0,68 & 12 \\
\hline$a b r / 57$ & jul/58 & 16 & 3 & 1,04 & 5 & 0,52 & 5 & 0,78 & 3 & 1,08 & 16 \\
\hline mai/63 & fev/64 & 10 & 3 & 0,53 & 1 & 0,28 & 3 & 0,24 & 3 & 0,40 & 10 \\
\hline mai/65 & jun/66 & 14 & 3 & 0,78 & 4 & 0,15 & 4 & 0,15 & 3 & 0,75 & 14 \\
\hline jul/68 & $\mathrm{abr} / 70$ & 22 & 6 & 0,38 & 5 & 0,61 & 5 & 0,13 & 6 & 0,19 & 22 \\
\hline $\mathrm{abr} / 72$ & $\mathrm{mar} / 73$ & 12 & 3 & 1,01 & 3 & 0,58 & 3 & 0,19 & 3 & 0,64 & 12 \\
\hline jul/76 & $\mathrm{mar} / 78$ & 21 & 6 & 0,04 & 4 & $-0,49$ & 5 & $-0,07$ & 6 & 0,04 & 21 \\
\hline$\Sigma$ (meses) & Média $\left({ }^{\circ} \mathrm{C}\right)$ & 117 & 30 & 0,45 & 26 & 0,21 & 31 & 0,28 & 30 & 0,43 & 117 \\
\hline \multicolumn{12}{|c|}{ EVENTOS LA NIÑA } \\
\hline \multirow{3}{*}{ Início } & \multirow{2}{*}{ Fim } & Duração & \multicolumn{2}{|c|}{$1 \mathrm{TC}$} & \multicolumn{2}{|c|}{$2 \mathrm{TC}$} & \multicolumn{2}{|c|}{$1 \mathrm{TS}$} & \multicolumn{2}{|c|}{$2 \mathrm{TS}$} & \\
\hline & & Total & Duração & Anomalias & Duração & Anomalias & Duração & Anomalias & Duração & Anomalias & \\
\hline & & meses & meses & $\left({ }^{\circ} \mathrm{C}\right)$ & Meses & $\left({ }^{\circ} \mathrm{C}\right)$ & Meses & $\left({ }^{\circ} \mathrm{C}\right)$ & Meses & $\left({ }^{\circ} \mathrm{C}\right)$ & $\Sigma$ \\
\hline $\mathrm{ago} / 49$ & $\mathrm{mar} / 51$ & 20 & 6 & $-0,59$ & 4 & $-0,51$ & 4 & $-0,25$ & 6 & $-0,44$ & 20 \\
\hline $\mathrm{mai} / 54$ & jan/57 & 33 & 8 & $-0,37$ & 7 & $-0,09$ & 9 & $-0,07$ & 9 & $-0,41$ & 33 \\
\hline mai/64 & fev/65 & 10 & 3 & $-0,25$ & 1 & $-0,47$ & 3 & $-0,29$ & 3 & $-0,28$ & 10 \\
\hline out/67 & $a b r / 68$ & 7 & 3 & 0,49 & 2 & $-0,13$ & & - & 2 & 0,27 & 7 \\
\hline $\mathrm{jul} / 70$ & jan/72 & 19 & 5 & $-0,07$ & 3 & $-0,25$ & 5 & $-0,09$ & 6 & $-0,27$ & 19 \\
\hline jun/73 & $\mathrm{abr} / 76$ & 35 & 9 & $-0,26$ & 8 & $-0,01$ & 9 & $-0,23$ & 9 & $-0,04$ & 35 \\
\hline$\Sigma$ (meses) & Média( $\left.{ }^{\circ} \mathrm{C}\right)$ & 124 & 34 & $-0,18$ & 25 & $-0,24$ & 30 & $-0,19$ & 35 & $-0,20$ & 124 \\
\hline
\end{tabular}

dos sistemas dinâmicos geradores de chuva, reduzindo a umidade do ar, inibindo a convecção e ocasionando períodos de seca em períodos climatológicos chuvosos.
Durante os meses com La Niña, observa-se na Tabela 5 que as temperaturas médias apresentaram tendências negativas de até $-0,29^{\circ} \mathrm{C}$ no primeiro trimestre chuvoso. Tais tendências nega- 
Tabela 4 - Anomalia trimestral da temperatura média do ar de superfície em Manaus, durante a fase quente da Oscilação Decadal do Pacífico, de 1976 a 1998.

\begin{tabular}{|c|c|c|c|c|c|c|c|c|c|c|c|}
\hline \multicolumn{12}{|c|}{ EVENTOS EL NIÑO } \\
\hline \multirow{2}{*}{ Início } & \multirow{2}{*}{ Fim } & Duração & \multicolumn{2}{|c|}{ 1TC } & \multicolumn{2}{|c|}{$2 \mathrm{TC}$} & \multicolumn{2}{|c|}{$1 \mathrm{TS}$} & \multicolumn{2}{|c|}{$2 \mathrm{TS}$} & \\
\hline & & Total & Duração & Anomalias & Duração & Anomalias & Duração & Anomalias & Duração & Anomalias & \\
\hline & & meses & meses & $\left({ }^{\circ} \mathrm{C}\right)$ & Meses & $\left({ }^{\circ} \mathrm{C}\right)$ & Meses & $\left({ }^{\circ} \mathrm{C}\right)$ & Meses & $\left({ }^{\circ} \mathrm{C}\right)$ & $\Sigma$ \\
\hline jul/79 & jul/80 & 13 & 3 & 0,51 & 3 & 0,85 & 4 & 0,05 & 3 & $-0,39$ & 13 \\
\hline $\mathrm{mar} / 82$ & $\mathrm{jul} / 83$ & 17 & 3 & 1,84 & 6 & 0,63 & 5 & 0,16 & 3 & 0,38 & 17 \\
\hline ago/86 & fev/88 & 19 & 6 & 0,47 & 3 & 0,62 & 4 & 0,57 & 6 & 0,03 & 19 \\
\hline $\mathrm{mar} / 90$ & jul/92 & 28 & 6 & 0,79 & 9 & 0,53 & 7 & 0,17 & 6 & 0,64 & 28 \\
\hline jan/93 & nov/93 & 11 & 2 & $-0,05$ & 3 & 0,38 & 3 & 0,32 & 3 & $-0,42$ & 11 \\
\hline mai/94 & $\mathrm{abr} / 95$ & 12 & 3 & $-0,09$ & 3 & 0,52 & 3 & $-0,18$ & 3 & 0,11 & 12 \\
\hline $\mathrm{abr} / 97$ & mai/98 & 14 & 3 & 1,14 & 5 & 0,74 & 3 & 1,49 & 3 & 1,71 & 14 \\
\hline$\Sigma$ (meses) & Média $\left({ }^{\circ} \mathrm{C}\right)$ & 114 & 26 & 0,66 & 32 & 0,61 & 29 & 0,37 & 27 & 0,29 & 114 \\
\hline \multicolumn{12}{|c|}{ EVENTOS LA NIÑA } \\
\hline \multirow{3}{*}{ Início } & \multirow{2}{*}{ Fim } & Duração & \multicolumn{2}{|c|}{$1 \mathrm{TC}$} & \multicolumn{2}{|c|}{$2 \mathrm{TC}$} & \multicolumn{2}{|c|}{$1 \mathrm{TS}$} & \multicolumn{2}{|c|}{$2 \mathrm{TS}$} & \\
\hline & & Total & Duração & Anomalias & Duração & Anomalias & Duração & Anomalias & Duração & Anomalias & \\
\hline & & meses & meses & $\left({ }^{\circ} \mathrm{C}\right)$ & Meses & $\left({ }^{\circ} \mathrm{C}\right)$ & meses & $\left({ }^{\circ} \mathrm{C}\right)$ & meses & $\left({ }^{\circ} \mathrm{C}\right)$ & $\Sigma$ \\
\hline set/83 & $\mathrm{mar} / 86$ & 31 & 9 & $-0,40$ & 7 & 0,16 & 6 & $-0,46$ & 9 & $-0,64$ & 31 \\
\hline $\mathrm{abr} / 88$ & out/89 & 19 & 3 & $-0,39$ & 5 & $-0,14$ & 6 & $-0,23$ & 5 & $-0,36$ & 19 \\
\hline ago/95 & fev/97 & 19 & 6 & 0,02 & 3 & 0,24 & 4 & 0,37 & 6 & 0,18 & 19 \\
\hline jul/98 & dez/00 & 30 & 7 & 0,05 & 6 & $-0,35$ & 8 & $-0,31$ & 9 & $-0,36$ & 30 \\
\hline$\Sigma$ (meses) & Média $\left({ }^{\circ} \mathrm{C}\right)$ & 99 & 25 & $-0,18$ & 21 & $-0,02$ & 24 & $-0,16$ & 29 & $-0,30$ & 99 \\
\hline
\end{tabular}

Tabela $\mathbf{5}$ - Anomalia trimestral da temperatura média do ar de superfície em Manaus, durante as fases do Evento ENOS.

\begin{tabular}{|c|c|c|c|}
\hline Grupo & El Niño & La Ninã & Neutros \\
\hline 1TC & $+0,50$ & $-0,29$ & $-0,11$ \\
\hline 2TC & $+0,39$ & $-0,25$ & $-0,08$ \\
\hline 1TS & $+0,24$ & $-0,19$ & $-0,14$ \\
\hline 2TS & $+0,31$ & $-0,25$ & $-0,17$ \\
\hline
\end{tabular}

tivas também foram coerentes e esperadas, já que os eventos de La Niñas na Amazônia Central geralmente produzem efeitos opostos aos eventos de El Niño, pois estimulam a liberação de calor latente na atmosfera e, conseqüentemente, são verificados maiores valores de precipitação pluviométrica e umidade relativa do ar que influenciam diretamente na redução dos valores da temperatura média do ar. Ainda na Tabela 5 observa-se tendências de anomalias negativas na temperatura média do ar durante os meses Neutros das águas do Pacífico tropical. Pelo exposto, os valores apresentados e discutidos da Tabela 5 ratificam as freqüências dos desvios de precipitação pluviométrica observadas durante os meses com El Niños, La Niñas e Neutros apresentados nas Figs. de 3-a a 3-c.

Na Tabela 6, também extraída dos valores das Tabs. 2, 3 e 4 e acrescida de meses Neutros, observa-se que as fases quentes da ODP coincidiram com maior freqüência de Niños, enquanto a fase fria da ODP com maior freqüência de Niñas. Também se observa ao longo do tempo uma redução do número de meses Neutros de 136 para 59 meses, que notadamente confere uma redução no período de transição entre Niños e Niñas. Conforme a Fig. 4 algumas diferenças ainda podem ser traçadas. Por exemplo, nesta figura se observam que os eventos de El Niño geralmente se destacam pelas magnitudes das anomalias de temperatura e La Niñas pela durabilidade dos eventos. Nesta figura destacamos os El Niños de 1982-83 e 1997-98 e as La Niñas de 1972-76 e 198386 como os eventos de maior influência nas variabilidades das temperaturas do ar em Manaus.

A Figura 5 apresenta a tendência linear global da série de dados, sendo observado um incremento nas temperaturas médias superficiais do ar de $+0,27 \pm 0,04^{\circ} \mathrm{C}$.

Entretanto, este aquecimento não tem sido constante ao longo da série estudada, conforme a Fig. 6, a qual foi analisada para os 


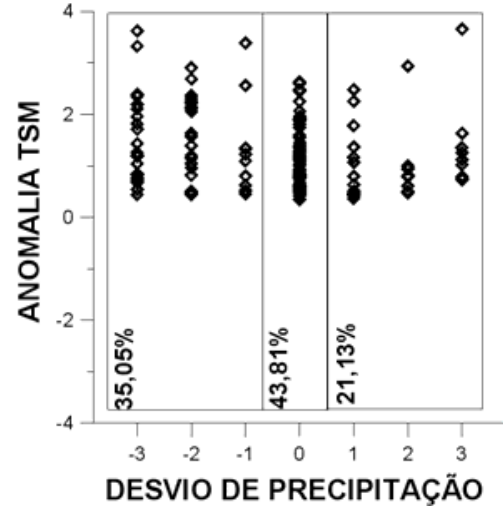

A

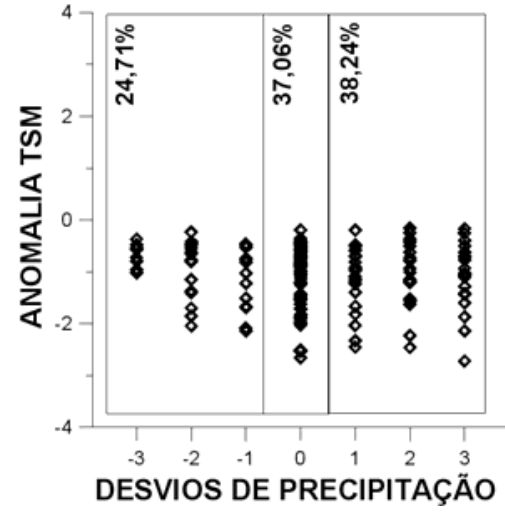

B

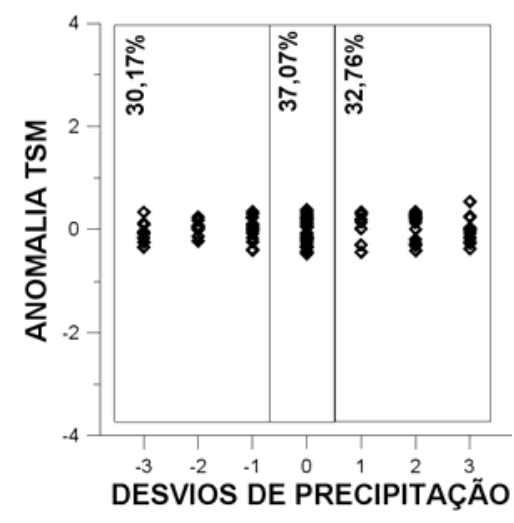

C

Figura 3 - Frequêência de meses secos e chuvosos entre 1961 a 2000 pelo cruzamento dos dados de anomalia de TSM do Pacífico da Região Niño 3.4 com o índice dos Decis, observados em Manaus. a) Meses com El Niño. b) Meses Neutros e c) Meses com La Niña.

Tabela 6 - Anomalia da temperatura média do ar de superfície em Manaus observadas durante as fases da ODP.

\begin{tabular}{|c|c|c|c|c|c|c|c|c|}
\hline Período & Anos & Fase & \multicolumn{2}{|c|}{ Niños } & \multicolumn{2}{c|}{ Niñas } & \multicolumn{2}{c|}{ Neutros } \\
\hline ODP & Quantidade & Sinal & ${ }^{\circ} \mathrm{C}$ & meses & ${ }^{\circ} \mathrm{C}$ & meses & ${ }^{\circ} \mathrm{C}$ & meses \\
\hline $1925-1946$ & 21 & + & $+0,19$ & 76 & $-0,37$ & 58 & $-0,06$ & 136 \\
\hline $1947-1976$ & 29 & - & $+0,34$ & 117 & $-0,20$ & 124 & $-0,19$ & 128 \\
\hline $1976-1998$ & 22 & + & $+0,48$ & 114 & $-0,16$ & 99 & $-0,10$ & 59 \\
\hline
\end{tabular}

períodos decadais intrafases da ODP. Em tese, tais tendências ratificam as informações atinentes das Tabelas 5 e 6 onde se observa que a variabilidade do microclima da cidade de Manaus tem sido modulado pelas tendências observadas no Oceano Pacífico.

Na Figura 6-B observa-se resfriamentos de $-0,23^{\circ} \mathrm{C}$ e $-0,33^{\circ} \mathrm{C}$ na seqüência das duas décadas internas à fase quente da ODP de 1925-46. Possivelmente a diminuiç̧ão dos valores das temperaturas é atribuída ao grande número de meses neutros, somados a uma quantidade significativa de La Niñas, indicadas na Tab. 6. Neste período, os eventos de El Niño foram fracos e, apesar de quantitativamente superiores aos meses com eventos de La Niña, não geraram impactos significativos nos valores das temperaturas médias do ar, como observados na Tab. 2. Na seqüência, a fase fria da ODP de 1947 a 1976 apresenta um período com forte aquecimento de $+0,44^{\circ} \mathrm{C}$, contudo, nota-se que na década anterior havia fortes anomalias negativas (Fig. 6-A); Todavia, as próximas duas décadas são seguidas com mais de 20 anos de tendências negativas, sendo de $-0,32^{\circ} \mathrm{Ce}-0,11^{\circ} \mathrm{C}$, respectivamente, os quais conferem com a maior freqüência de La Niñas e meses Neutros, conforme as Figs. 3-b e 3-c, pois propiciaram um maior número de meses com desvios positivos de precipitação.

Ainda na Fig. 6-A no período de 1976 a 1998 (fase quente da ODP), observa-se duas décadas com tendências de aquecimento de $+0,16^{\circ} \mathrm{C} \mathrm{e}+0,25^{\circ} \mathrm{C}$, respectivamente. Na segunda década observa-se novamente a nítida influência dos clássicos eventos de El Niño 1982-83 e 1997-98, considerados os eventos de maior magnitude e de maior impacto econômico e social ao redor do globo terrestre.

As variabilidades interdecadais apresentadas na Fig. 6-A permitem concluir que grande parte do incremento registrado na temperatura do ar em Manaus ocorreu em dois períodos, nas décadas de 1950 e a partir da década de 1980, com aquecimento acentuado durante a década de 1990. Isto não pode ainda ser considerado como padrão de mudança climática, e entende-se por variabilidade climática, visto o recente período de análise, como também da forte associação com as oscilações climáticas naturais do Oceano Pacífico.

Com base nos dados analisados é possível fazer previsões de que os próximos 20 a 30 anos poderão apresentar tendências negativas nas temperaturas médias do ar na região da cidade de Manaus, visto que, segundo Molion (2004), estamos desde 1999 novamente numa fase fria da ODP.

Por tudo exposto, verificamos haver boa consistência entre os valores de anomalias das TSM do Pacííico, na região Niño 


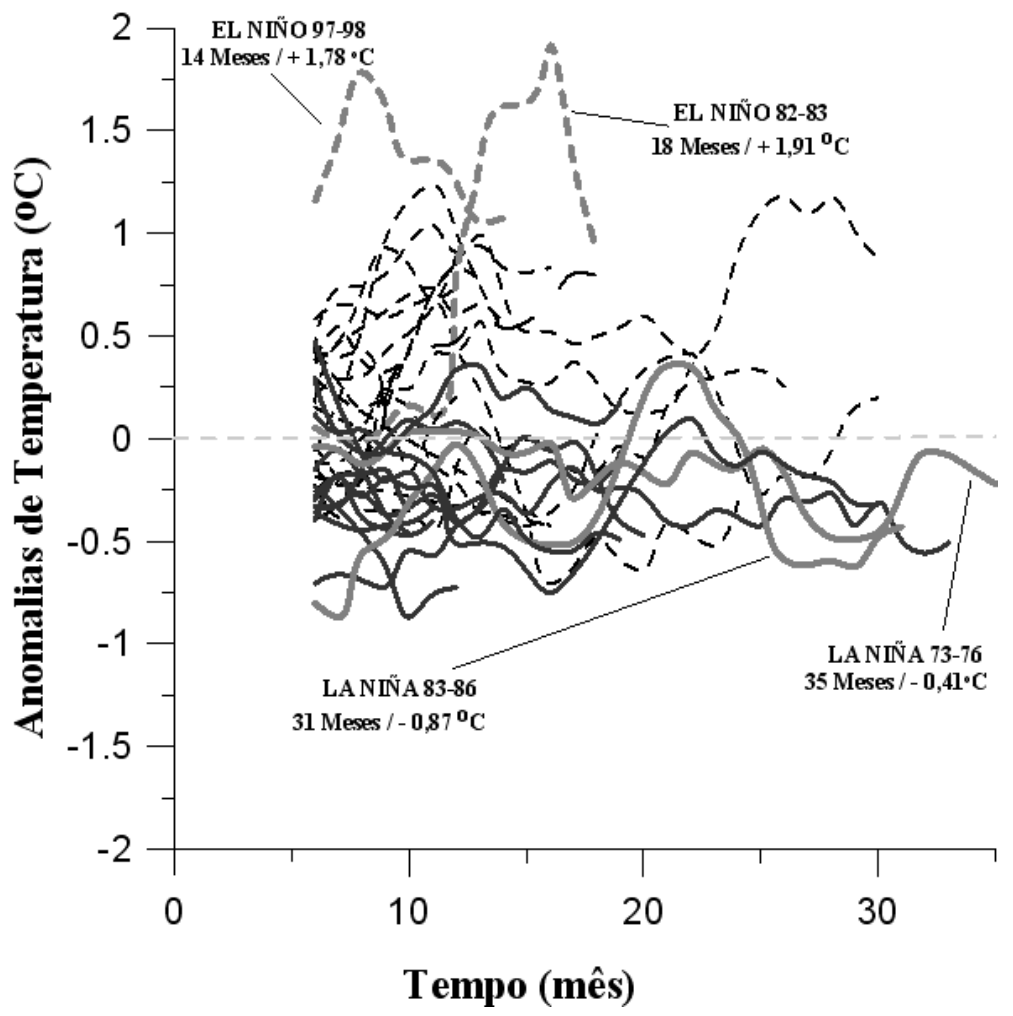

Figura 4 - Anomalias de temperatura média do ar de superfície observadas em Manaus de 1921 a 2000, durante os meses com Eventos El Niño / Oscilação do Sul.

3.4 e padrões da ODP, com os valores de anomalias de temperatura do ar e precipitação pluviométrica na região de Manaus. Assim, existe um entendimento real de que o comportamento das condições térmicas superficiais da bacia do Pacífico tem importância primária no câmbio das variabilidades climáticas.

\section{DA INFERÊNCIA PRÉ-INSTRUMENTAL}

Dos onze locais perfilados, todos apresentam medidas de temperatura em intervalos discretos de 5 metros, sendo que cinco dos perfis são representativos de locais com cobertura vegetal, doravante denominados de LCCV (Figs. 7-a a 7-e) e outros seis são representativos de locais sem cobertura vegetal, doravante denominados de LSCV (Figs. 8-a a 8-f). As Figuras 7 e 8 representam 0 conteúdo de informações transientes e de longa-data. Tais informações são os resíduos de temperatura obtidos através da diferença entre os valores calculados de $\mathbf{T}_{0}$ e 0 observado. Embora tais perfis registrem valores diferentes de temperatura, eles têm, no entanto, configurações semelhantes, principalmente às maiores profundidades do perfil.

Dos perfis do tipo LCCV, determinamos gradientes positi- vos desde a superfície do subsolo, exceto na Fig.7-a, na qual a presença de fontes térmicas internas, tais como águas subterrâneas, reações químicas e fraturamentos (Silva, 2003), que podem ter produzido os desvios observados na configuração normal do perfil. Já nos perfis do tipo LSCV, verificou-se intensos gradientes negativos desde a superfície até profundidades de 30 a 80 metros, seguidos de uma zona com fluxo de calor nulo, denominada por Araujo (1999) de "zona de cotovelo térmico" e de uma zona de inversão térmica em profundidades médias de $78 \mathrm{~m}$, a partir da qual a temperatura aumenta linearmente com a profundidade.

Estas observações nos permitem admitir que a Zona Termicamente Perturbada (ZTP) se encontra dividida em dois setores: a porção superior está associada com informações transientes ( $\left.I_{T R}\right)$ devido a variabilidades climáticas anuais, enquanto que a porção inferior, após a zona do cotovelo térmico, está associada às informações de longa data (lLD). Deste modo, passamos a admitir os termos ZTP ITR E ZTP ILD, como designativos da divisão da Zona Termicamente Perturbada, respectivamente.

Na Tabela 7 apresentamos os valores pertinentes obtidos pelas perfilagens geotérmicas e representam as zonas ZTP ${ }_{\text {ITR }}$ ZTP ILD 


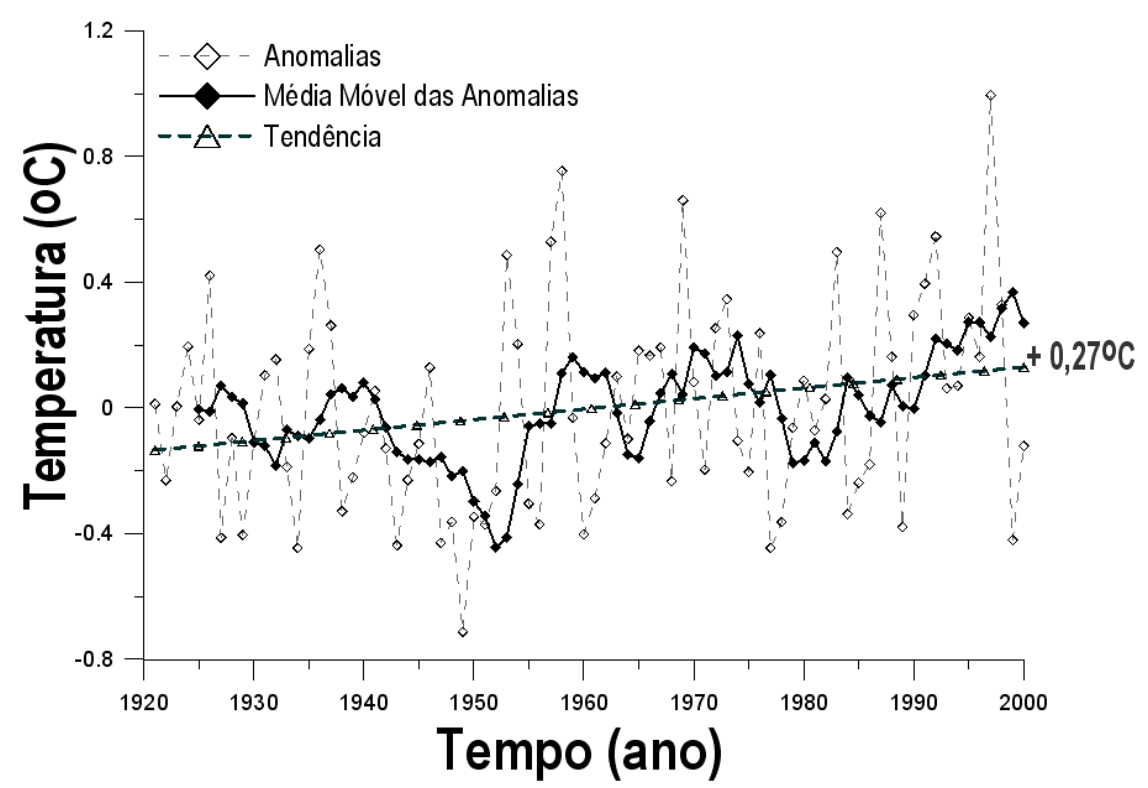

Figura 5 - Tendência linear observada da temperatura média do ar de superfície em Manaus, de 1921 a 2000.

e ZTE, com suas respectivas divisões de profundidade. Na região

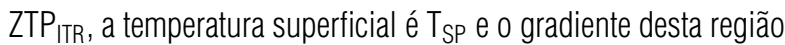
é calculado até a profundidade inicial da ZTP calculou-se os demais gradientes para suas respectivas faixas. A divisão média entre as zonas térmicas perturbada e estável são visualizadas na Fig. 9.

Na região ZTPITR, os gradientes negativos identificados nos perfis LSCV e positivos nos perfis LCCV são informações transientes e excelentes indicadores da variabilidade climática Iocal anual. Todavia, tais gradientes superficiais em locais do tipo LSCV fornecem informações transientes pelo uso do solo, devido à alteração do balanço de energia pela retirada da floresta. Conforme a Tabela 7, observamos que as perturbações no campo das temperaturas referentes às informações térmicas de longa data persistem até as profundidades médias de 165 metros. Abaixo destas profundidades médias não encontramos perturbações oriundas do campo climático de superfície. Tais regiões do subsolo, denominadas de ZTE, fornecem o valor de $\mathrm{G}_{\text {ZTE }}$ (definido na Eq. 1), o qual fornece o perfil geotérmico inicial e informações relevantes de longa data.

Com base nos dados das perfilagens geotérmicas, os valores médios das $T_{\text {SP }}$ são $26,75 \pm 0,20^{\circ} \mathrm{C}$ e $28,37 \pm 0,51^{\circ} \mathrm{C}$ e amplitudes térmicas de $0,55^{\circ} \mathrm{C}$ e $1,38^{\circ} \mathrm{C}$ para os perfis LCCV e LSCV, respectivamente. Os valores médios de $T_{S P}$, nos perfis LSCV, são $1,62^{\circ} \mathrm{C}$ mais elevadas que os valores nos perfis LCCV. Tal diferença atribui-se às mudanças ocorridas no balanço de energia do solo perante a substituição das áreas de floresta por pastagens.

Na Tabela 7, nos perfis LCCV, referente aos valores médios de $G_{\text {zTp }}$ e $G_{\text {ZTE }}$ (Eqs. 2 e 1), encontramos $5 \times 10^{-3} \pm 1,5 \times$ $10^{-3}{ }^{\circ} \mathrm{C} . \mathrm{m}^{-1}$ e $2,42 \times 10^{-2} \pm 4 \times 10^{-4}{ }^{\circ} \mathrm{C} . \mathrm{m}^{-1}$, respectivamente. Para os perfis LSCV, encontramos $4,9 \times 10^{-3} \pm$ $3,3 \times 10^{-3}{ }^{\circ} \mathrm{C} . \mathrm{m}^{-1}$ e $2,43 \times 10^{-2} \pm 5 \times 10^{-4}{ }^{\circ} \mathrm{C} \cdot \mathrm{m}^{-1}$, respectivamente. Nota-se que os valores de $\mathrm{G}_{\text {ZTE }}$ e $\mathrm{G}_{\text {ZTP }}$ são ligeiramente próximos nos dois tipos de perfis. Tal aproximação deve-se a ausência, nestas regiões, de perturbações transientes de superfície. Desta forma, atinente aos dados baseados na Tabela 7, pode-se determinar, especificamente para a região estudada, que a partir das profundidades médias de 78 metros (ZTP ITR $)$ e 165 metros (ZTE), os perfis adquirem padrões com inclinações semelhantes. Os valores médios de $\mathrm{G}_{\text {ZTP }}$ e $\mathrm{G}_{\text {ZTE }}$ para 0 conjunto global dos perfis foram de $4,9 \times 10^{-3} \pm 2,5 \times 10^{-3}{ }^{\circ} \mathrm{C} . \mathrm{m}^{-1}$ e $2,43 \times 10^{-2} \pm 5 \times 10^{-4}{ }^{\circ} \mathrm{C} . \mathrm{m}^{-1}$, respectivamente.

Os valores médios calculados de $T_{S A}$ e $T_{L D}$ nos perfis do tipo LCCV foram de $26,72 \pm 0,11^{\circ} \mathrm{C}$ e $23,53 \pm 0,40^{\circ} \mathrm{C}$, respectivamente, tendo havido, portanto, de acordo com esses valores, um acréscimo nas temperaturas médias superficiais do solo de $3,19 \pm 0,42^{\circ} \mathrm{C}$. No que concerne aos valores médios nos perfis LSCV, calculou-se o valor médio de $26,79 \pm 0,09^{\circ} \mathrm{C}$ para $\mathrm{T}_{S A} \mathrm{e}$ $23,64 \pm 0,67^{\circ} \mathrm{C}$ para $\mathrm{T}_{\mathrm{LD}}$, representando acréscimo de $3,15 \pm$ $0,65^{\circ} \mathrm{C}$ nos valores das temperaturas médias anuais superficiais do solo. Os valores médios globais (LCCV + LSCV) calculados 


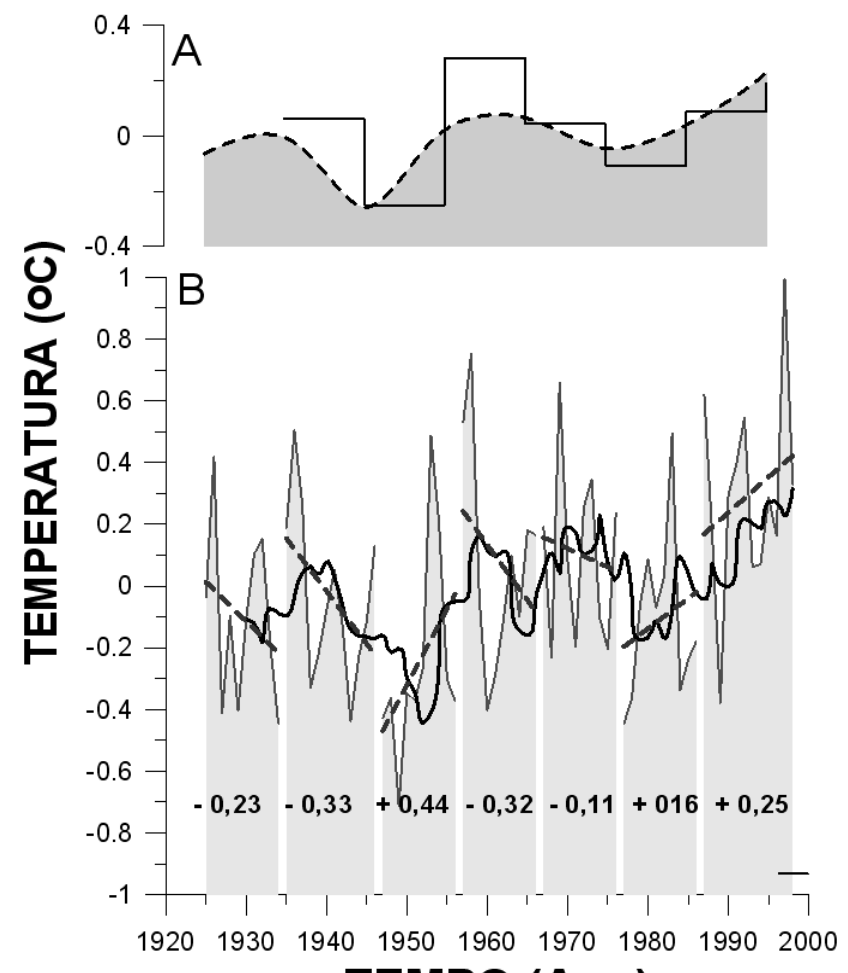

TEMPO (Ano)

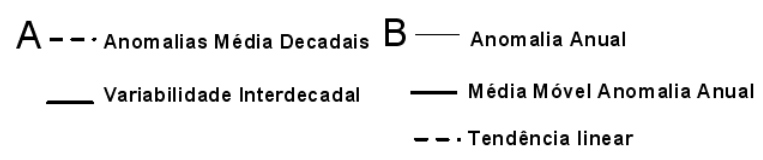

Figura 6 - Variabilidades e tendências observadas da temperatura média do ar de superfície em Manaus entre 1921 a 2000. A - Variabilidade intrafase da ODP. B - Variabilidade interdecadal.

de $\mathrm{T}_{S A}$ e $\mathrm{T}_{\mathrm{LD}}$ foram $26,76 \pm 0,10^{\circ} \mathrm{C}$ e $23,59 \pm 0,54^{\circ} \mathrm{C}$, respectivamente, representados na Fig. 9 pelos perfis geotérmicos inicial e final, enquanto que os resíduos térmicos que indicam a taxa de mudança no microclima em superfície estão representados na Fig. 10 , sendo de $+3,17^{\circ} \mathrm{C} \pm 0,53^{\circ} \mathrm{C}$. De outra forma, isto representa um acréscimo médio nos valores de temperatura superficial do solo entre $+2,64^{\circ} \mathrm{C} e+3,70^{\circ} \mathrm{C}$. Em regiões de latitudes médias e árticas do hemisfério norte foram determinados acréscimos pontuais da temperatura média superficiais do solo entre 2 e $5^{\circ} \mathrm{C}$ (Roy et al., 1971; Lachenbruch \& Marshall, 1986).

Observa-se que todos os perfis geotérmicos apresentados indicam um acréscimo nos valores das temperaturas superficiais do solo, onde 0 acréscimo nos perfis $\mathrm{LCCV}$ foi $+0,04^{\circ} \mathrm{C}$ maior que nos perfis LSCV. Contudo, tal valor de $0,04^{\circ} \mathrm{C}$ é muito inferior aos desvios padrões e não consideramos como um sinal de relativa importância, significando que a taxa de acréscimo de longa data nas temperaturas médias superficiais do solo são praticamente iguais para superfícies com ou sem cobertura vegetal, por serem determinadas a partir de regiões do subsolo atinentes a informações de longa data.

0 mesmo não pode ser válido para as recentes variabilidades climáticas anuais, visto serem função apenas do fluxo de radiação

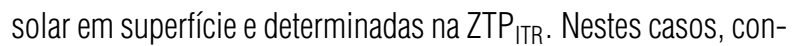
forme apresentado na Fig. 11, observa-se nos perfis LCCV perfilados nos anos de 1991-93-96 e 97, pouco ou nenhum sinal de recente variabilidade climática anual em superfície, cerca de $+0,03 \pm 0,18^{\circ} \mathrm{C}$, enquanto que nos perfis LSCV verificou-se uma recente variabilidade climática anual de $+1,58 \pm 0,51^{\circ} \mathrm{C}$. 0 valor médio para LSCV + LCCV foi de $+0,87 \pm 0,89^{\circ} \mathrm{C}$. Os elevados valores de dispersão dos desvios padrões representam alta variabilidade entre as informações transientes. Contudo, sempre apresentarão valores máximos e mínimos, que mediados nos fornecem uma boa solução para uma resolução anual. 

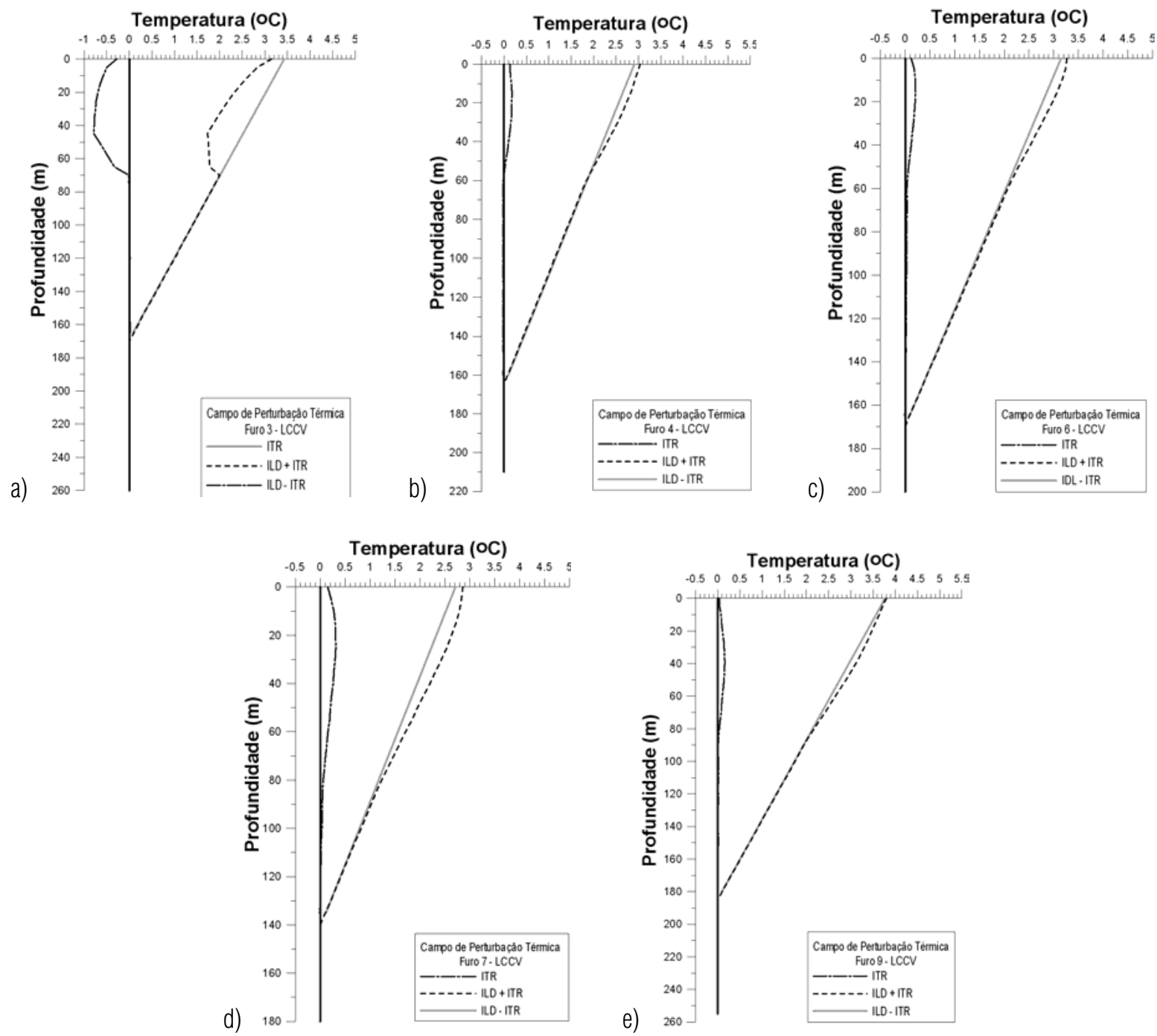

Figura 7 - Informações transientes e de longa data dos perfis geotérmicos de locais com cobertura vegetal (LCCV) na cidade de Manaus.

Para ratificar que os dados transientes fornecem boas resoluções anuais, analisamos as perturbações transientes relativas aos perfis LCCV que, conforme a Tabela 7, fazem referência aos anos de 1991, 1993, 1996 e 1997. Associou-se esta informação com a média móvel de 5 meses das anomalias das temperaturas médias do ar, referente aos anos completos de 1991, 1993, 1996 e até abril de 1997, conforme a Tabela 5. A análise foi realiza somente até 0 mês de abril de 1997, devido ao clássico El Niño de abril de 1997 a março de 1998, o qual poderia causar severas discrepâncias nos resultados.

Observou-se pela Tabela 8 que 0 desvio na temperatura média do ar foi de $+0,17 \pm 0,08^{\circ} \mathrm{C}$. Tal valor está de acordo com as informações transientes dos perfis LCCV de $+0,03 \pm 0,18^{\circ} \mathrm{C}$,
0 qual oscila de $-0,15^{\circ} \mathrm{C}$ a $+0,21^{\circ} \mathrm{C}$. Isto ratifica a ligação entre as informações transientes do subsolo de locais com cobertura vegetal com as variabilidades climáticas detectadas em superfície.

Nos perfis do tipo LSCV, tais comparações são muito problemáticas, visto que as mudanças na cobertura vegetal alteram significativamente 0 balanço de energia na superfície do solo (Araujo, 1999; Souza et al., 1989). Isto é verificado pela discrepância dos dados, contudo, os dados obtidos nos perfis LSCV mostram a importância das modificações no microclima por forçantes antrópicas.

A Figura 12 representa a espacialização dos resíduos de temperatura das informações de longa-data (Fig. 12a) e tran- 

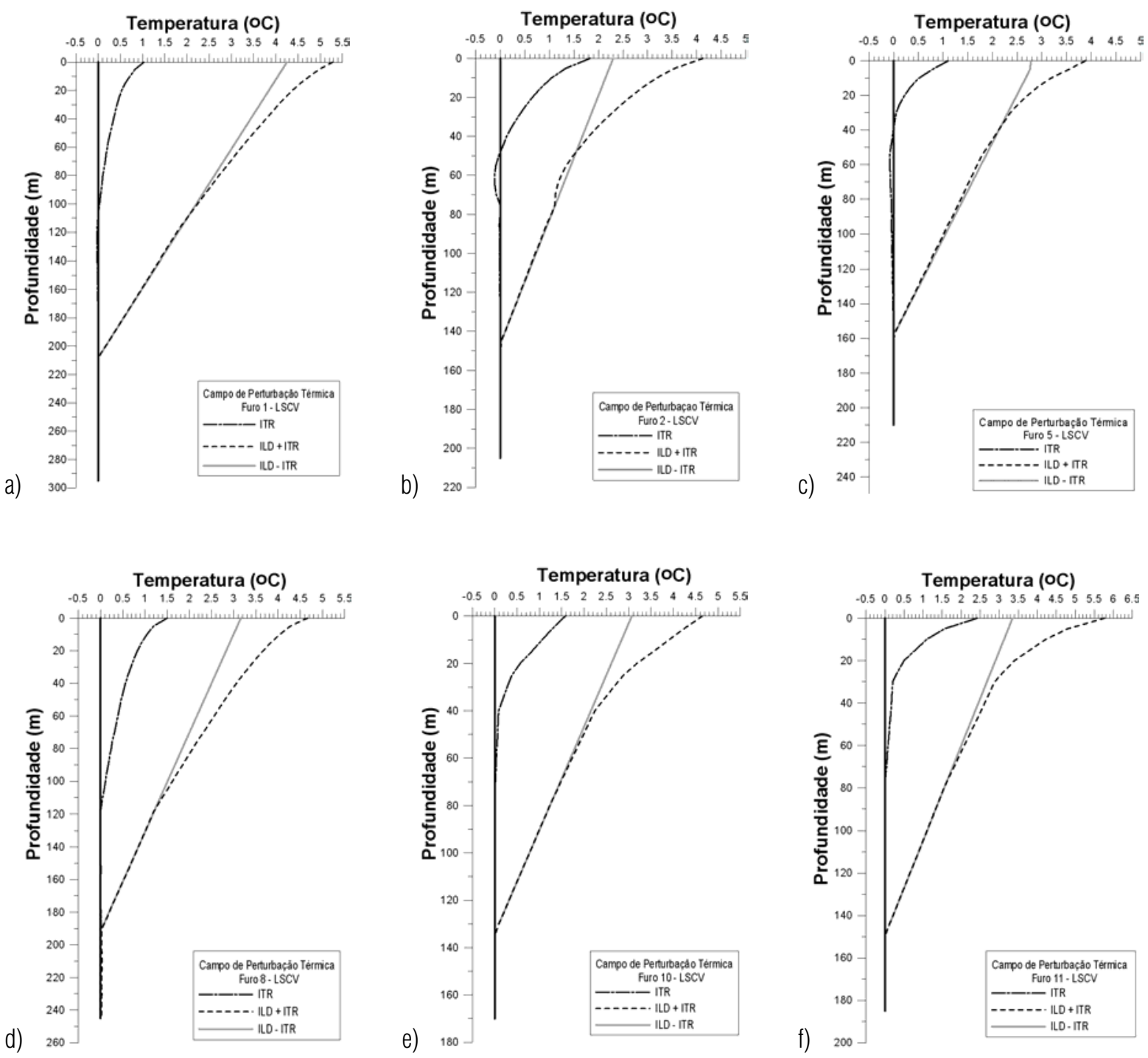

Figura 8 - Informações transientes e de longa data dos perfis geotérmicos de locais sem cobertura vegetal (LSCV) na cidade de Manaus.

sientes (Fig. 12b).

Os resultados ratificam a importância da cobertura vegetal sobre os valores registrados da temperatura superficial do solo, na área urbana da cidade de Manaus. Desta forma, o setor sul da área urbana de Manaus, de maior atividade urbanística e marco da ocupação nos século XIX, encontramos um incremento superior a $3,8^{\circ} \mathrm{C}$ no valor das temperaturas médias superficiais de Ionga-data, estimado desde a segunda metade do século XIX pela ocupação do solo, enquanto que os setores noroeste e nordeste do limite urbano, por ainda possuírem áreas com boa cobertura vegetal e menor tempo de ocupação urbana, apresentam incrementos de até $2,8^{\circ} \mathrm{C}$ nas temperaturas médias superficiais. Relativo às variabilidades recentes do microclima (ITR), ocorridas no período de observação ou da perfilagem, observou-se que os setores com boa cobertura vegetal (setores leste e oeste) apresentam variabilidades muito pequenas, cujos valores concordam com as pequenas frações de anomalias sazonais e anuais registradas nas estações meteorológicas, enquanto que os setores sem cobertura vegetal são palco de altas variabilidades nos valores de temperatura de superfície, com incrementos anuais de até $+2,5^{\circ} \mathrm{C}$. Deste modo, ratificamos que as comparações dos dados meteorológicos com os resultados dos perfis geotérmicos do tipo LSCV são inadequadas para as análises de mudanças e variabilidades climáticas provocados por mecanismos naturais e somente devem ser analisadas em conjunto, quando se procura comparar os efeitos das interferências antropogênicas versus as naturais. 
Tabela 7 - Gradientes da Geotermia Rasa em Manaus.

\begin{tabular}{|c|c|c|c|c|c|c|c|c|c|c|c|c|c|}
\hline \multirow{3}{*}{ Furo } & \multirow{3}{*}{$\begin{array}{c}\text { Ano da } \\
\text { perfilagem }\end{array}$} & \multirow{3}{*}{$\begin{array}{c}\text { Tipo de } \\
\text { Cobertura Vegetal }\end{array}$} & \multicolumn{3}{|c|}{$\mathrm{ZTP}_{\mathrm{ITR}}$} & \multicolumn{5}{|c|}{ ZTP $_{\text {ILD }}$} & \multicolumn{3}{|c|}{ ZTE } \\
\hline & & & $\mathrm{T}_{\mathrm{SP}}$ & $Z$ & $\mathrm{G}_{\mathrm{ITR}}\left(10^{-3}\right)$ & $\mathrm{Ti}$ & Zi & Tf & Zf & $G_{Z T P}\left(10^{-3}\right)$ & $\mathrm{T}$ & Z & $\mathrm{G}_{\mathrm{ZTE}}\left(10^{-2}\right)$ \\
\hline & & & $\left({ }^{\circ} \mathrm{C}\right)$ & (m) & $\left({ }^{\circ} \mathrm{C} / \mathrm{m}\right)$ & $\left({ }^{\circ} \mathrm{C}\right)$ & (m) & $\left({ }^{\circ} \mathrm{C}\right)$ & (m) & $\left({ }^{\circ} \mathrm{C} / \mathrm{m}\right)$ & $\left({ }^{\circ} \mathrm{C}\right)$ & (m) & $\left({ }^{\circ} \mathrm{C} / \mathrm{m}\right)$ \\
\hline 3 & 1991 & LCCV & 26,47 & 0,00 & 7,50 & 27,03 & 75 & 27,38 & 165 & 3,90 & 29,55 & 260 & 2,40 \\
\hline 4 & 1993 & LCCV & 26,77 & 0,00 & 5,00 & 27,07 & 60 & 27,81 & 160 & 7,40 & 28,97 & 210 & 2,50 \\
\hline 6 & 1997 & LCCV & 27,02 & 0,00 & 4,40 & 27,24 & 50 & 27,92 & 175 & 5,40 & 28,55 & 200 & 2,40 \\
\hline 7 & 1996 & LCCV & 26,76 & 0,00 & 3,70 & 27,06 & 80 & 27,37 & 145 & 4,80 & 28,20 & 180 & 2,40 \\
\hline 9 & 1996 & LCCV & 26,73 & 0,00 & 3,30 & 27,03 & 90 & 27,37 & 185 & 3,60 & 29,08 & 255 & 2,40 \\
\hline Média & - & LCCV & 26,75 & 0,00 & 4.80 & 27,09 & 71 & 27,57 & 166 & 5,00 & 28,87 & 221 & 2,42 \\
\hline 1 & 1989 & LSCV & 27,79 & 0,00 & $-5,80$ & 27,15 & 110 & 27,49 & 205 & 3,60 & 29,70 & 295 & 2,40 \\
\hline 2 & 1991 & LSCV & 28,63 & 0,00 & $-1,52$ & 27,49 & 75 & 28,14 & 145 & 9,30 & 29,66 & 205 & 2,50 \\
\hline 5 & 1996 & LSCV & 27,88 & 0,00 & $-2,00$ & 27,08 & 40 & 27,77 & 155 & 6,00 & 29,04 & 210 & 2,40 \\
\hline 8 & 1994 & LSCV & 28,46 & 0,00 & $-6,10$ & 27,79 & 110 & 28,39 & 190 & 7,50 & 29,69 & 245 & 2,40 \\
\hline 10 & 1994 & LSCV & 28,27 & 0,00 & $-1,75$ & 26,78 & 85 & 26,84 & 140 & 1,10 & 27,71 & 170 & 2,50 \\
\hline 11 & 1996 & LSCV & 29,17 & 0,00 & $-2,88$ & 26,87 & 80 & 26,98 & 150 & 1,60 & 27,84 & 185 & 2,40 \\
\hline Média & - & LSCV & 28,37 & 0,00 & $-1,56$ & 27,19 & 83 & 27,60 & 164 & 4,90 & 28,94 & 218 & 2,43 \\
\hline Média & - & LCCV + LSCV & 27,63 & 0,00 & $-6,30$ & 27,14 & 78 & 27,59 & 165 & 4,90 & 28,91 & 220 & 2,43 \\
\hline
\end{tabular}

\section{Temperatura (OC)}

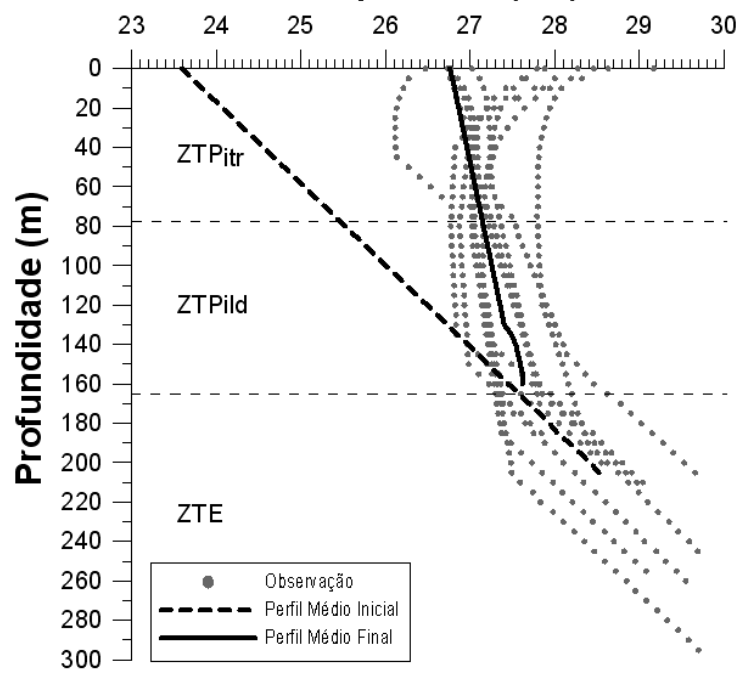

Figura 9 - Perfis geotérmicos como indicador de mudanças climáticas na superfície do solo por atividades antrópicas em Manaus.

\section{CONCLUSÕES}

Os resultados deste estudo enfatizam os motivos das variabilidades e mudanças climáticas das temperaturas médias do ar e do solo de superfície nas abrangências da cidade de Manaus, considerando a importância das oscilações oceânico-atmostéricas e os efeitos do uso do solo na estrutura geotermal rasa, sob condições diferenciadas de cobertura vegetal superficial e sua manifestação a respeito da história climática da cidade de Manaus.
Analisando o cruzamento dos dados de TSM da região Niño 3.4 com os dados de temperatura média do ar e precipitação da Estação Meteorológica de Manaus, verificamos que os desvios da média observados na cidade são modulados pelas freqüências de meses com El Niño, La Niña e Neutros, regidos em escala maior pela ODP, causando um incremento linear observado de $0,27 \pm 0,04^{\circ} \mathrm{C}$ nas temperaturas médias do ar durante os últimos 80 anos. Grande parte deste incremento ocorreu em dois 


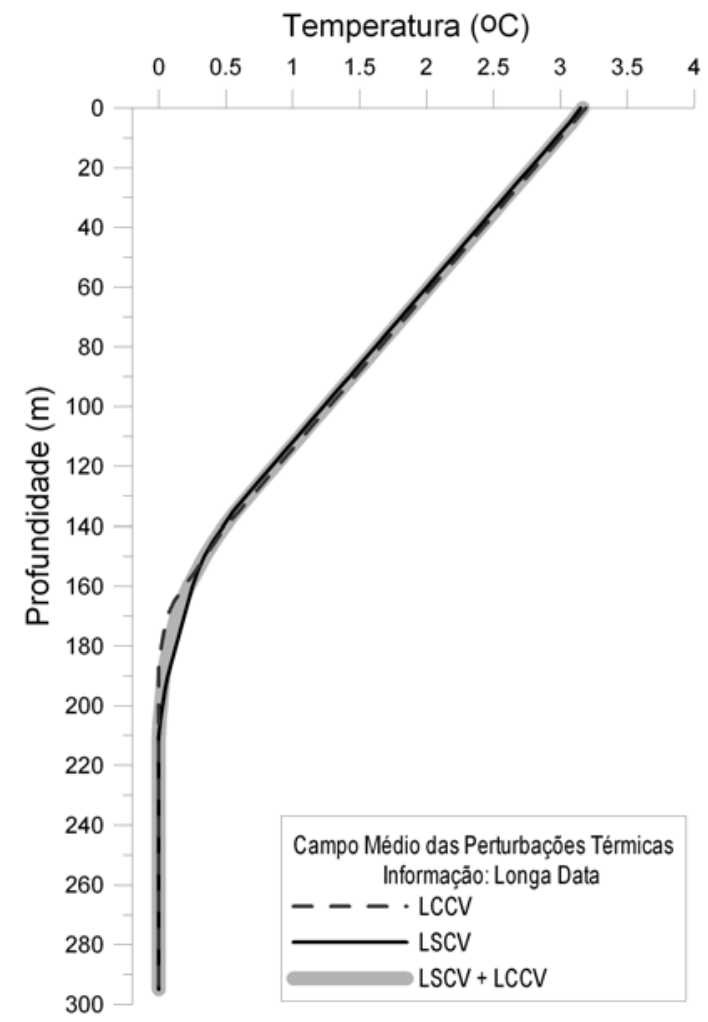

Figura 10 - Dados das perturbações térmicas de longa-data do subsolo de Manaus.

Tabela 8 - Médias móveis de 5 meses das anomalias de temperatura média do ar de superfície em Manaus.

\begin{tabular}{|c|c|c|c|c|c|c|c|c|c|c|c|c|c|}
\hline \multicolumn{11}{|c|}{ Anomalias $\left({ }^{\circ} \mathrm{C}\right)$} \\
\hline Ano & Jan & Fev & Mar & Abr & Mai & Jun & Jul & Ago & Set & Out & Nov & Dez & Anual \\
\hline 1991 & 0,4 & 0,4 & 0,6 & 0,3 & 0,3 & 0,1 & 0,2 & 0,2 & 0,1 & 0,0 & 0,0 & 0,4 & $\mathbf{0 , 1 3}$ \\
\hline 1993 & $-0,1$ & 0,1 & 0,0 & 0,0 & $-0,1$ & 0,2 & 0,4 & 0,4 & 0,4 & 0,4 & 0,1 & $-0,2$ & $\mathbf{0 , 1 4}$ \\
\hline 1996 & 0,3 & 0,0 & $-0,1$ & $-0,1$ & 0,1 & 0,2 & 0,3 & 0,4 & 0,2 & 0,2 & 0,1 & 0,1 & $\mathbf{0 , 1 5}$ \\
\hline 1997 & 0,1 & 0,2 & 0,1 & 0,1 & - & - & - & - & - & - & - & - & $\mathbf{0 , 1 3}$ \\
\hline Média & 0,2 & 0,2 & 0,2 & 0,1 & 0,1 & 0,2 & 0,3 & 0,3 & 0,2 & 0,2 & 0,1 & 0,1 & $\mathbf{0 , 1 7}$ \\
\hline
\end{tabular}

períodos, na década 1950 e a partir da década de 1980, com aquecimento acentuado durante a década de 1990.

Determinamos com importância o período climático associado à fase fria da ODP (1947 a 1976). Tal período destacou-se por apresentar tendências negativas nos valores das temperaturas médias do ar de superfície. Considerando que desde 1999 estamos numa nova fase fria da ODP, é provável que os próximos 20 ou 30 anos apresentem tendências negativas de temperatura do ar em Manaus.

Em base na geotermia rasa, determinamos 0 valor da temperatura média anual atual da cidade de Manaus de 26,76 \pm $0,10^{\circ} \mathrm{C}$. Tal valor está em conformidade com 0 valor obtido via observação instrumental de $26,65 \pm 0,33^{\circ} \mathrm{C}$. A diferença é coerente, visto 0 fato de que tais valores se encontrarem numa interface mecanicamente turbulenta. Deste modo, as localidades que não possuem dados meteorológicos, podem obter tais informações através de estudos geotérmicos.

As análises das perfilagens indicam um incremento médio da temperatura média anual na cidade de Manaus de 3,17 \pm $0,53^{\circ} \mathrm{C}$, estimado desde a segunda metade do século XIX, e diretamente modulado pela ocupação do homem na região mediante a alteração do balanço energético da superfície pelo desmatamento 


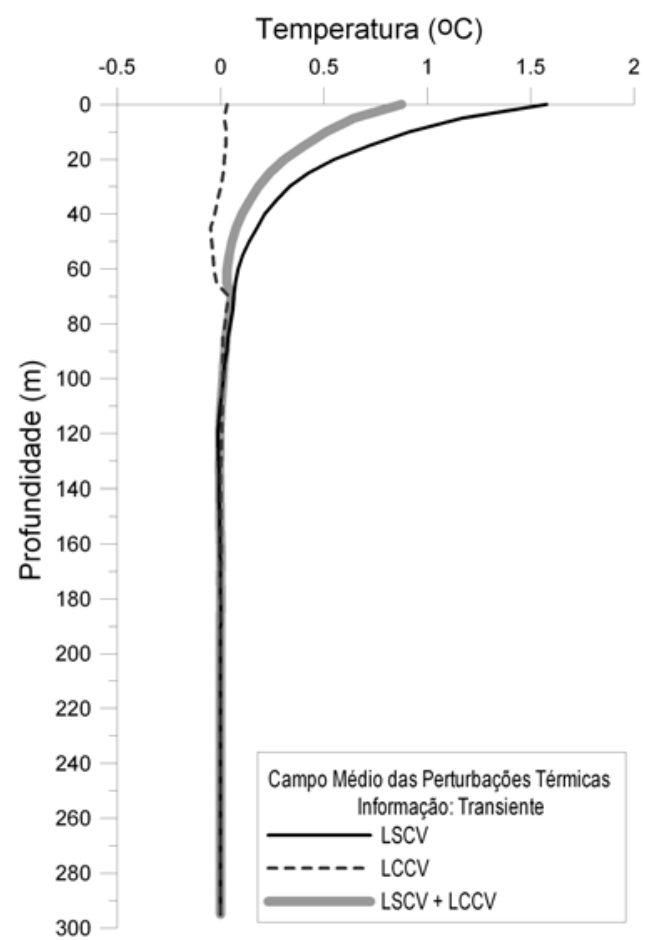

Figura 11 - Dados das perturbações transientes de temperatura do subsolo de Manaus.

e urbanismo. Tal modificação da cobertura vegetal insere um incremento na temperatura média anual atual da superfície do solo em até $1,62^{\circ} \mathrm{C}$. Valor semelhante $\left(+1,58 \pm 0,51^{\circ} \mathrm{C}\right)$ também foi encontrado quando analisadas somente as porções transientes dos perfis, indicando que tal taxa pode ser indicador de que o desmatamento provoca alterações climáticas na superfície de forma quase-instantânea.

Observou-se que as perturbações transientes no regime térmico raso, nos locais com cobertura vegetal são bons indicadores das variabilidades anuais detectadas em superfície por estações meteorológicas. 0 resultado com base no método utilizado é conclusivo, mas necessita de experimentos controlados de monitoramento contínuo. Os perfis geotérmicos de locais sem cobertura vegetal somente inferem mudanças climáticas forçadas por atividades antrópicas.

\section{AGRADECIMENTOS}

Ao Instituto Nacional de Meteorologia por disponibilizar registros instrumentais de superfície e ao Laboratório de Geofísica do Departamento de Geociências do Instituto de Ciências Exatas da Universidade Federal do Amazonas que forneceu a infra-estrutura necessária para a execução do projeto.

\section{REFERÊNCIAS}

ACEITUNO P. 1988. On the Functioning of the Southern Oscillation in the South America Sector - Part I: Surface Climate. Monthly Weather Review, 116(3): 505-524.

ARAUJO RLC. 1987. Geotermia Rasa em Belém. Tese de Doutorado. Universidade Federal do Pará (PA). $149 \mathrm{p}$.

ARAUJO RLC. 1999. Contribuição da Geotermia Rasa aos Estudos Ambientais. Manaus. Ed. Universidade do Amazonas. 88 p.

ASTIER JL. 1975. Geofísica Aplicada a la Hidrogeologia, Madrid, Parainfo. $344 \mathrm{p}$.

BECK AE. 1965. Techniques of Measuring Heat Flow on Land. In: LEE W., Terrestrial Heat Flow. Washington. American Geophysical Union. p. 24-57.

BECK AE. 1982. Precision Logging of Temperatures Gradients and the Extraction of Past Climate. Tectonophysics, 83(1/2): 1-11.

BELTRAMI H \& HARRIS RN. 2001. Inferences of Climate Change from Geothermal Data. Global and Planetary Change. 29: 149-152.

BIRCH F. 1948. The Effects of Pleistocene Climatic Variations upon Geothermal Gradients, Am. J. Sci., 246: 729-760.

BOWEN R. 1966. Paleotemperature Analyses. Methods in Geochemistry and Geophysics. Elsevier. Publishing, $265 \mathrm{pp}$. 


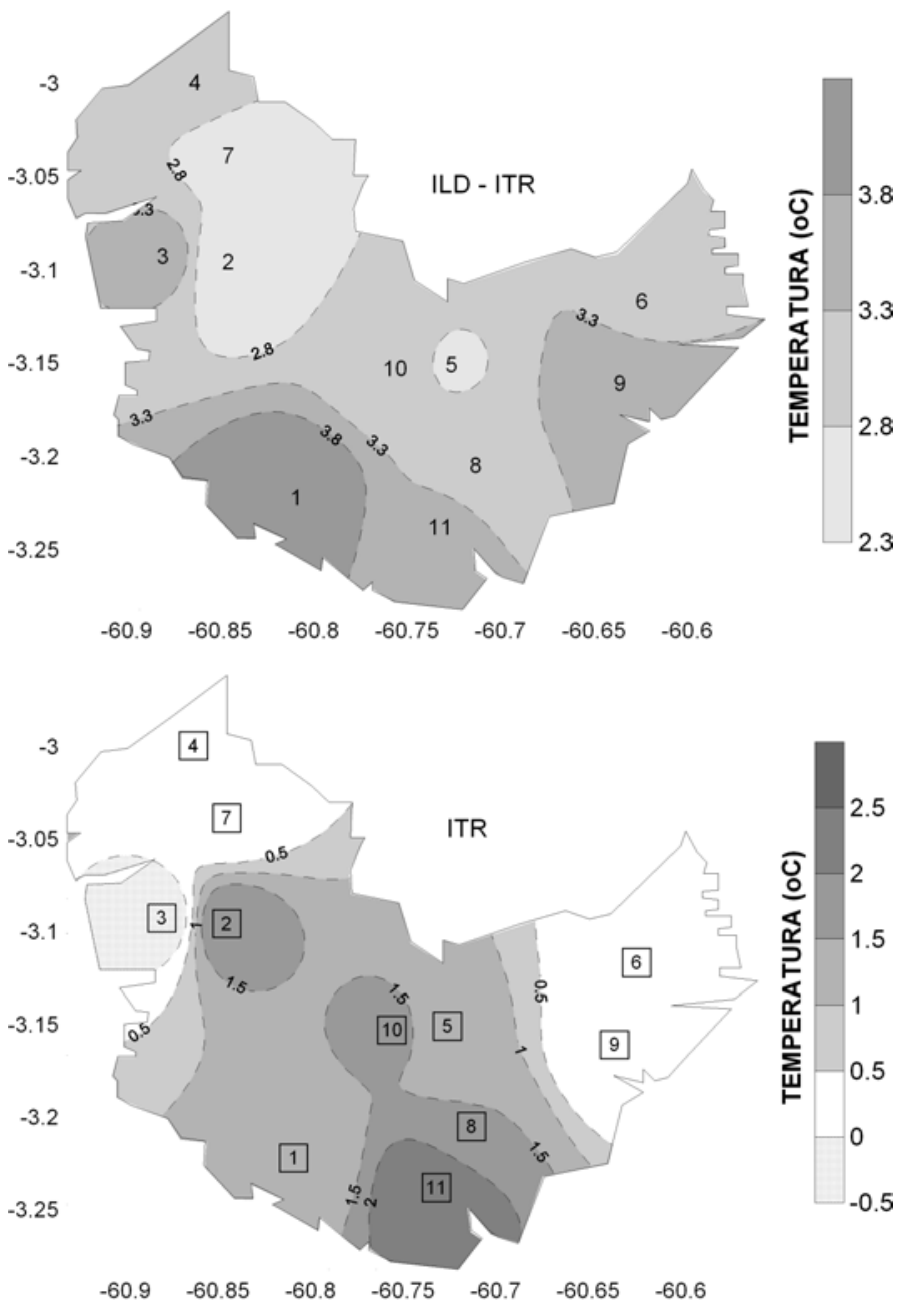

Figura 12 - Espacialização dos resíduos de temperatura superficial do solo, das informações de a) longa-data e b) transientes.

CARSLAW HS \& JAEGER JC. 1959. Conduction of Heat in Solids. $2^{\text {a }}$ ed. Oxford. Clarendon Press. 527 p.

CERMAK V. 1971. Underground Temperatures and Inferred Climatic Temperature of the Past Millennium, Palaeogeogr., Palaeoclimatol., Palaeoecol., 10: 1-19.

GIBBS WJ \& MAHER JV. 1967. Rainfall Deciles as Drought Indicators. Commonwealth Bureau of Meteorology Bulletin, No. 48, Melbourne.

HAMZA VM. 1998. A Proposal for Continuous Recording of Subsurface Temperatures at Sites of Geomagnetic Field Observatories. Revista Geofísica do Instituto Panamericano de Geografía e Historia - IPGH, IPGH, 48: 183-198.

HAMZA VM. 1991. Evidências Geotérmicas sobre Variações Climáticas Recentes no Hemisfério Sul. $2^{\text {nd }}$ International Congress of the Brazilian Geophysical Society, Salvador (BA), p. 971-976.

IBGE. Instituto Brasileiro de Geografia e Estatística. 2005. Disponível em <http://www.ibge.gov.br>. Acesso em: 11 set. 2005.

IPCC. 2001. The Scientific Basis. Published for the Intergovernmental Panel on Climate Change. New York: Cambridge University Press. p. 101-104.

KAYANO MT \& MOURA AD. 1986. 0 El Niño de 1982-83 e a Precipitação sobre a América do Sul. Revista Brasileira de Geofísica. 4(2): 201-214.

KOUSKY VE \& CAVALCANTI IFA. 1984. Eventos Oscilação Sul / El Nino. Características, Evolução e Anomalias de Precipitação. Ciência e Cultura, 36(11): 1888-1899.

LACHENBRUCH A \& MARSHALL BV. 1986. Changing Climate: Geothermal Evidence from Permafrost in the Alaska Artic. Science 234: 689-696.

MANTUA NJ, HARE Y, ZHANG JM, WALLACE \& FRANCIS RC. 1997. A Pacific Interdecadal Climate Oscillation with Impacts on Salmon Production. Bulletin of the American Meteorological Society, 78: 1069-1079. 
MOLION LCB. 1987. Micrometeorology of Amazonian Rainforest. In: DICKINSON RE (Ed.). The Geophysiology of Amazonian, John Wiley and Sons, UNU, 255-270.

MOLION LCB. 1991. Climate Variability and its Effects on Amazonian Hydrology. In: BRAGA Jr. BPF \& FERNANDEZ-JAUREGUI CA (Ed.). Water Management of the Amazon basin, UNESCO/ABRH, p. 261-274.

MOLION LCB. 2004. Aquecimento Global, Manchas Solares, El Niño e Oscilação Decadal do Pacífico. Disponível em: $<$ http://www.geofiscal.eng.br/aquecimentoglobal.htm>. Acesso em: 23 mar. 2005.

RAO VB \& HADA K. 1987. Characteristics of Rainfall over Brazil: Seasonal Variations and Connections with the Southern Oscillation. INPE 4432-PRE/1234, São José dos Campos, São Paulo, Brazil.

PONTES FILHO RP. 2000. Estudos de História do Amazonas. Manaus: Editora Valer. $240 \mathrm{p}$.

RIEHL H. 1965. Tropical Meteorology. First Edition. McGraw-Hill Book Company, Inc. $426 p$.

ROY RF, BLACKWELL DD \& DECKER ER. 1971. Continental Heat Flow. In: ROBERTSON R. The Nature of Soil. New York: Mc Graw-Hill. p. 506-543.

SALATI E. 1987. Modificações da Amazônia nos Últimos 300 anos: Suas Conseqüências Sociais e Ecológicas. IV Encontro Regional de Tropicologia em Brasília, 14-26.

SERRA PN. 2002. Determinação da Profundidade de Influência da Perturbação Térmica Sazonal Gerada pelo Aquecimento Solar na Região Metropolitana de Manaus. Universidade Federal do Amazonas. Dissertação de Mestrado. 80 p.

SILVA RM. 2003. Influência Ambiental sobre a Estrutura Geotermal Rasa. Dissertação de Mestrado. Universidade Federal do Amazonas (AM). $102 p$.

SOUZA JRS, ARAUJO RLC \& MAKINO M. 1989. Heat Transfer and Thermal Properties of the Subsoil in Belém. Revista Brasileira de Geofísica, 7(1): 19-28.

TRENBERT KE. 1997. The Definition El Niño. Bulletin of the American Meteorological Society, 2771-2777.

TRENBERT KE \& STEPANIAK DP. 2001. Indices of El Niño Evolution. J. Climate., 14: 1697-1701.

\section{NOTAS SOBRE OS AUTORES}

Flavio Natal Mendes de Oliveira. Recebeu o título de meteorologista pela Universidade Federal de Pelotas em 1999. Mestre em Geociências pela Universidade Federal do Amazonas, em 2006. Trabalha como meteorologista no $1^{\circ}$ Distrito de Meteorologia do Instituto Nacional de Meteorologia (INMET) em Manaus.

Rutenio Luiz Castro de Araújo. Graduado em Física pela Universidade Federal do Rio de Janeiro, em 1973. Mestre em Geofísica pela Universidade de São Paulo, em 1977 e Doutor em Geofísica pela Universidade Federal do Pará, em 1987. Atualmente é professor titular no Departamento de Geociências da Universidade Federal do Amazonas, onde exerce a função de docente e de pesquisador desde 0 ano de 1980. Atua na área de Geofísica Aplicada, principalmente em Geofísica Ambiental.

João da Silva Carvalho. Recebeu o título de geólogo pela Universidade Federal do Amazonas, em 1981 e de Mestre em geofísica pela Universidade Federal do Pará, em 1987. Atualmente é professor adjunto no Departamento de Geociências da Universidade Federal do Amazonas. Possui como linha de pesquisa a geofísica aplicada.

Clauzionor Lima da Silva. Bacharel em Geologia em 1993 pela Universidade Federal do Amazonas (UFAM). Concluiu o Mestrado e o Doutorado em Geologia Regional, ambos desenvolvidos na UNESP (Rio Claro), em 1997 e 2005, respectivamente. Desde 1993 é professor do Departamento de Geociências da UFAM. Atua nas linhas de pesquisa Geofísica Ambiental e Geologia Estrutural. 